Cochrane Database of Systematic Reviews

\title{
Continuous versus intermittent antibiotics for bronchiectasis
} (Review)

Donovan T, Felix LM, Chalmers JD, Milan SJ, Mathioudakis AG, Spencer S

Donovan T, Felix LM, Chalmers JD, Milan SJ, Mathioudakis AG, Spencer S.

Continuous versus intermittent antibiotics for bronchiectasis.

Cochrane Database of Systematic Reviews 2018, Issue 6. Art. No.: CD012733.

DOI: 10.1002/14651858.CD012733.pub2.

www.cochranelibrary.com 
TABLE OF CONTENTS

HEADER 1

ABSTRACT

PLAIN LANGUAGE SUMMARY

BACKGROUND

OBJECTIVES

METHODS

RESULTS

Figure 1.

DISCUSSION

AUTHORS' CONCLUSIONS

ACKNOWLEDGEMENTS

REFERENCES

CHARACTERISTICS OF STUDIES

APPENDICES

CONTRIBUTIONS OF AUTHORS

DECLARATIONS OF INTEREST

SOURCES OF SUPPORT

DIFFERENCES BETWEEN PROTOCOL AND REVIEW

INDEX TERMS

1

2

3

4

4

7

8

9

9

10

11

19

24

28

28

28

28

28 
[Intervention Review]

\section{Continuous versus intermittent antibiotics for bronchiectasis}

Tim Donovan ${ }^{1}$, Lambert M Felix², James D Chalmers ${ }^{3}$, Stephen J Milan4, Alexander G Mathioudakis ${ }^{5}$, Sally Spencer6

1 Medical and Sport Sciences, University of Cumbria, Lancaster, UK. 2Nuffield Department of Orthopaedics, Rheumatology and Musculoskeletal Sciences (NDORMS), University of Oxford, Oxford, UK. 3University of Dundee, Ninewells Hospital and Medical School, Dundee, UK. ${ }^{4}$ Medical School, Lancaster University, Lancaster, UK. ${ }^{5}$ Division of Infection, Immunity and Respiratory Medicine, University of Manchester, Manchester, UK. ${ }^{6}$ Postgraduate Medical Institute, Edge Hill University, Ormskirk, UK

Contact address: Tim Donovan, Medical and Sport Sciences, University of Cumbria, Lancaster, UK. tim.donovan@cumbria.ac.uk.

Editorial group: Cochrane Airways Group.

Publication status and date: New, published in Issue 6, 2018.

Citation: Donovan T, Felix LM, Chalmers JD, Milan SJ, Mathioudakis AG, Spencer S. Continuous versus intermittent antibiotics for bronchiectasis. Cochrane Database of Systematic Reviews 2018, Issue 6. Art. No.: CD012733. DOI: 10.1002/14651858.CD012733.pub2.

Copyright (c) 2018 The Cochrane Collaboration. Published by John Wiley \& Sons, Ltd.

\section{A B S T R AC T}

\section{Background}

Bronchiectasis is a chronic airway disease characterised by a destructive cycle of recurrent airway infection, inflammation and tissue damage. Antibiotics are a main treatment for bronchiectasis. The aim of continuous therapy with prophylactic antibiotics is to suppress bacterial load, but bacteria may become resistant to the antibiotic, leading to a loss of effectiveness. On the other hand, intermittent prophylactic antibiotics, given over a predefined duration and interval, may reduce antibiotic selection pressure and reduce or prevent the development of resistance. This systematic review aimed to evaluate the current evidence for studies comparing continuous versus intermittent administration of antibiotic treatment in bronchiectasis in terms of clinical efficacy, the emergence of resistance and serious adverse events.

\section{Objectives}

To evaluate the effectiveness of continuous versus intermittent antibiotics in the treatment of adults and children with bronchiectasis, using the primary outcomes of exacerbations, antibiotic resistance and serious adverse events.

\section{Search methods}

On 1 August 2017 and 4 May 2018 we searched the Cochrane Airways Review Group Specialised Register (CAGR), CENTRAL, MEDLINE, Embase, PsycINFO, CINAHL, and AMED. On 25 September 2017 and 4 May 2018 we also searched www.clinicaltrials.gov, the World Health Organization (WHO) trials portal, conference proceedings and the reference lists of existing systematic reviews.

\section{Selection criteria}

We planned to include randomised controlled trials (RCTs) of adults or children with bronchiectasis that compared continuous versus intermittent administration of long-term prophylactic antibiotics of at least three months' duration. We considered eligible studies reported as full-text articles, as abstracts only and unpublished data.

\section{Data collection and analysis}

Two review authors independently screened the search results and full-text reports.

\section{Main results}

We identified 268 unique records. Of these we retrieved and examined 126 full-text reports, representing 114 studies, but none of these studies met our inclusion criteria. 


\section{Authors' conclusions}

No randomised controlled trials have compared the effectiveness and risks of continuous antibiotic therapy versus intermittent antibiotic therapy for bronchiectasis. High-quality clinical trials are needed to establish which of these interventions is more effective for reducing the frequency and duration of exacerbations, antibiotic resistance and the occurrence of serious adverse events.

\section{PLAIN LANGUAGE SUMMARY}

\section{Are antibiotics more effective when given continuously or intermittently to people with bronchiectasis?}

\section{Background}

Bronchiectasis is an incurable lung disease characterised by repeated chest infections. Antibiotics are a main form of treatment and can be taken long term to prevent chest infections from developing. This could be continuously or intermittently for a fixed period of time. However, we do not currently know which approach is the most effective for reducing the frequency and duration of exacerbations, managing antibiotic resistance and minimising side effects.

\section{Study Characteristics}

On 1 August 2017 we searched a wide range of sources to find clinical trials for our review. We found 268 potentially relevant results but on closer examination none of the studies met our review criteria and none could be included.

\section{Authors' conclusions}

There is no high-quality evidence about whether continuously administered or intermittently administered antibiotics are safer and more helpful for people with bronchiectasis. More research is needed to evaluate which one of these methods is better for reducing chest infections, limiting resistance to antibiotic therapy and reducing serious side effects. 


\section{B A C K G R O U N D}

\section{Description of the condition}

Bronchiectasis is a chronic airway disease characterised by abnormal destruction and dilation of the large airways, bronchi and bronchioles (Pasteur 2010). It is characterised radiologically by permanent dilation of the bronchi, and clinically by a syndrome of cough, sputum production and recurrent respiratory infections (Chalmers 2014). The pathogenesis of bronchiectasis can be explained by the vicious cycle theory, whereby an initial insult to the airway leads to bronchial wall inflammation and damage, and disordered mucociliary clearance, predisposing the patient to chronic or recurrent infection resulting in further airway damage (Cole 1986; Chalmers 2013). An understanding of this cycle of persistent bacterial colonisation, chronic inflammation of the bronchial mucosa, and progressive tissue destruction is central to the management of bronchiectasis as strategies to arrest both inflammatory and bacterial components are required to limit the progression of lung injury (Cole 1997; Pasteur 2010). Bacteria most commonly isolated from the airways of patients with bronchiectasis include non-typeableHaemophilus influenzae, Pseudomonas aeruginosa,Streptococcus pneumoniae,Staphylococcus aureus and Moraxella catarrhalis (Foweraker 2011). Colonising pathogens such as $P$ aeruginosa, $H$ influenzae and $M$ catarrhalis also commonly display antimicrobial resistance arising from intrinsic resistance mechanisms or frequent exposure to antimicrobial agents.

Approximately half of presenting cases are classified as idiopathic. The most commonly assigned aetiology is postinfectious bronchiectasis, a heterogenous group including patients with childhood respiratory infections like pertussis, bacterial pneumonia or tuberculosis (Pasteur 2010). Diagnosis is based on identification of one or more abnormally dilated bronchi using high-resolution computed tomography (HRCT) (Chang 2010; Pasteur 2010). The main aims of therapeutic management are reduction of symptoms such as cough, breathlessness and expectoration, reduction of the number and duration of exacerbations and improvement in quality of life (Pasteur 2010; Chalmers 2015).

Bronchiectasis was once considered a relatively rare disease but recent studies have suggested increasing prevalence, particularly in women and those aged over 60 years (Weycker 2005; Roberts 2010; Seitz 2010), and higher prevalence rates in low- and middle-income countries (Habesoglu 2011). Prevalence in Germany in 2013 was estimated at 67 cases per 100,000 general population (Ringshausen $2015)$. In the UK, point prevalence rates per 100,000 rose from 350.5 to 566.1 in women and from 301.2 to 485.5 in men over a nine-year period, reflecting an increase of more than $60 \%$ and approximately 263,000 adults living with bronchiectasis in 2013 (Quint 2016). Similarly, incidence rates per 100,000 person-years over the same period rose from 21.2 to 35.2 in women and from 18.2 to 26.9 in men, a 63\% increase, with over 15,000 new cases in 2013. Average European mortality rates per 100,000 general population are estimated at 0.3 in 27 of the 28 EU countries and at 0.2 in nine non-EU countries, based on 2005 to 2009 data (European Lung White Book 2013). Recent UK age-adjusted mortality rates are 2.26 times higher in women and 2.14 times higher in men compared with the general population (Quint 2016).
The disease has a significant impact on children, with worse quality of life in younger children and those with more frequent exacerbations (Kapur 2012). Bronchiectasis is also more common in some indigenous groups where prevalence may be as high as 16 per 1000 among southwest Alaskan children and 15 per 1000 in Australian Aboriginal and Torres Strait Islander children (Chang 2002). Furthermore, one study reported an incidence of 3.7 per 100,000 per year among New Zealand children aged under 15 years. This equates to an overall prevalence of 1 per 3000 children and 1 per 625 Pacific children (Twiss 2005). It also demonstrates that the incidence rate among children in New Zealand is almost seven times higher than those from Finland (Twiss 2005).

An improvement in diagnosis resulting from easier access to high-quality CT scanners, and increased awareness of symptoms common to bronchiectasis and other lung diseases, have been cited as factors contributing to increased prevalence (Goeminne 2016).

Bronchiectasis places an increasing burden on healthcare systems internationally (Chalmers 2015; Redondo 2016), with patients experiencing a high rate of exacerbations, hospital admissions and attributable mortality (Chalmers 2015). Data from the European bronchiectasis registry show that approximately half of bronchiectasis patients have two or more exacerbations per year and a third are hospitalised at least once a year (Polverino 2017). Patients colonised with $P$ aeruginos $a$ and those with a more frequent annual exacerbation rate have an accelerated decline in lung function, reduced health-related quality of life (measured using the St George's Respiratory Questionnaire, SGRQ), increased risk of hospitalisation and increased mortality risk (Evans 1996; Wilson 1997; Martínez-García 2007, Polverino 2017). A history of exacerbations, and particularly severe exacerbations, low body mass index, chronic bacterial infection, low forced expiratory volume in one second $\left(\mathrm{FEV}_{1}\right)$ per cent of predicted, a higher proportion of affected lobes and more breathlessness are also associated with an increased risk of hospitalisation and mortality (Seitz 2010; Chalmers 2014; Rogers 2014).

This is particularly the case with $P$ aeruginosa infection. A systematic review of observational studies identified that $P$ aeruginosa infection is associated with a three-fold increase in mortality risk, an almost seven-fold increase in risk of hospital admission and an average of one additional exacerbation per patient per year.

Bronchiectasis care is associated with substantial resource use. A recent Spanish study reported a mean direct annual medical cost for adult patients with bronchiectasis of EUR 4671, escalating with disease severity (de la Rosa 2016). Furthermore, factors such as FEV $_{1}$ percentage predicted, age, Pseudomonas colonisation and hospitalisation may independently influence health care costs. A USA-based study reported an annual increase of USD 2319 in overall costs and USD 1607 in respiratory-related costs in patients with bronchiectasis compared with matched case-controls, attributed primarily to an increase of two outpatient visits and 1.6 respiratoryrelated visits per patient per year (Joish 2013).

\section{Description of the intervention}

Antibiotics aiming to treat bacterial infections of the respiratory tract, or to control bacterial colonisation, or both, represent a central component of the treatment of bronchiectasis, as they reduce bacterial load, inflammation and consequent tissue 
destruction in the airways (Chalmers 2012). Long-term prophylactic antibiotics, administered for more than three months, have proved effective for patients with frequent bronchiectasis exacerbations or those with fewer exacerbations causing significant morbidity, as they appear to decrease the frequency and severity of exacerbations, at the expense of a significant increase in the risk of emerging drug resistance (Hnin 2015). Patients taking continuous antibiotics are more than three times at risk of bacterial resistance compared to those who do not (Hnin 2015). Pathogens isolated in the sputum cultures of these patients during an exacerbation or at stable disease, such as $P$ aeruginosa, $H$ influenzae or $M$ catarrhalis, commonly display antimicrobial resistance arising from intrinsic resistance mechanisms or frequent exposure to antimicrobial agents. There is also risk of antibiotic-related adverse effects, such as hearing impairment and cardiotoxicity (Serisier 2013).

Randomised controlled trials (RCTs) have evaluated different modes of administration, namely oral, intravenous and inhaled, and different classes of antibiotics including but not limited to macrolides, quinolones or polymyxins. Two strategies for the administration of long-term antibiotics have been described: (I) continuous and (ii) intermittent administration. In contrast to continuous, intermittent refers to the repeated prophylactic administration of courses of antibiotics with predefined duration and intervals. Examples include one short course of antibiotics every month; month on and month off; or during the winter months. We intended this review to include intermittent antibiotic therapy where administration is at predefined regular intervals over a duration of at least three weeks, and where patients are not receiving concomitant prophylactic antibiotics. We intended to compare continuous versus intermittent administration of longterm prophylactic antibiotics for at least three months.

\section{How the intervention might work}

There is a strong relationship between airway bacterial infection and disease morbidity in bronchiectasis; for example, patients chronically infected with $P$ aeruginosa have a three-fold increase in mortality, a 6.5 times increase in hospital admission rate and an average of one additional exacerbation per patient per year, when compared to patients not chronically infected with $P$ aeruginosa (Finch 2015). Other commonly isolated bacteria such as $H$ influenzae and $M$ catarrhalis also drive an increase in neutrophilic inflammation (Chalmers 2012); and they are associated with an increased risk of severe exacerbations (Chalmers 2014). Antibiotic treatment aims to suppress neutrophilic inflammation, reduce bacterial load and thereby improve clinical outcomes (Brodt 2014). Continuous administration of antibiotic treatment is based on the assumption that chronic infection cannot be eradicated, and must therefore be continuously suppressed to prevent a return of bacterial load, increased inflammation and a recurrence of symptoms (Haworth 2014).

The argument against continuous exposure to antibiotics is that it leads to increased bacterial resistance and consequently treatment may lose its effectiveness (Chalmers 2015). On the contrary, intermittent administration of antibiotics might remove or limit the antibiotic selection pressure and, consequently, prevent the development of resistance, although intermittent antibiotics could also be less effective. While data are lacking on the impact of intermittent versus continuous administration of antibiotics on the development of antibiotic resistance among patients with bronchiectasis, there is some indirect evidence. For example, in a large retrospective analysis of mechanically-ventilated patients with nosocomial infections ( $40 \%$ chronic lung disease), an interval of at least 20 days between serial courses of antibiotics was associated with a $24 \%$ reduction in development of resistance (Hui 2013).

An additional advantage of intermittent antibiotic administration is a reduced treatment burden to patients, as continuous administration may result in more side effects as a result of higher cumulative exposure of the patient to antibiotics.

\section{Why it is important to do this review}

While long-term antibiotic treatments given both orally and via inhalation are part of the standard care for patients with bronchiectasis (Chalmers 2015), there is no agreement on the optimal method of delivery of antibiotic therapies. It is common practice to administer both oral and inhaled antibiotics daily (Altenburg 2013; Haworth 2014), on alternate days (Wong 2012), month on and month off (Barker 2014), or during the winter months when patients may experience more exacerbations. International guidelines are unable to comment on which method of antibiotic administration is most effective or is associated with the lowest rates of adverse events or antibiotic resistance. A European Respiratory Society/European Bronchiectasis Network (EMBARC) task force produced 22 consensus recommendations for future research into bronchiectasis, including "Studies should evaluate whether cyclic or continuous administration of longterm antibiotics is superior both in terms of clinical efficacy and the emergence of resistance" (Aliberti 2016). As this was determined to be an important clinical question by both patients and physicians, this systematic review was intended to evaluate the current evidence for continuous versus intermittent administration of antibiotic treatment in bronchiectasis.

\section{O B JECT IVES}

To evaluate the effectiveness of continuous versus intermittent antibiotics in the treatment of adults and children with bronchiectasis, using the primary outcomes of exacerbations, antibiotic resistance and serious adverse events.

\section{METHODS}

\section{Criteria for considering studies for this review \\ Types of studies}

We planned to include randomised controlled trials (RCTs) and cluster-randomised trials. We also planned to include cross-over studies, but to only use data from the first pre-cross-over phase to eliminate potentially irreversible carry-over effects (e.g. antibiotic resistance). We also planned to include studies reported as full text, those published as abstract only, and unpublished data.

\section{Types of participants}

We planned to include adults and children ( $<18$ years) diagnosed with bronchiectasis by bronchography, or computed tomography who reported daily signs or symptoms, such as cough, sputum production, or those with recurrent episodes of chest infections. Studies would have been excluded if participants had received a diagnosis of cystic fibrosis (CF) or active allergic bronchopulmonary aspergillosis. We planned to analyse data on children and adults separately. 


\section{Types of interventions}

We aimed to compare continuous versus intermittent administration of long-term prophylactic antibiotics of at least three months' duration. The delivery method was to be the same in all study groups, e.g. nebulised versus nebulised, in order to isolate the effect of the antibiotic rather than the delivery device.

We considered intermittent administration of antibiotics, provided that there were predefined regular intervals of antibiotic administration followed by a duration of at least three weeks when participants did not receive prophylactic antibiotics (e.g. one short course of antibiotics every month; month on and month off; or during the winter months). We considered antibiotics delivered without intervals of no antibiotics for the duration of the study to be continuous.

\section{Types of outcome measures}

\section{Primary outcomes}

1. Exacerbations (frequency, proportion with one or more, duration, time to next exacerbation), defined using study authors' criteria.

2. Antibiotic resistance, defined as either the presence of antibiotic resistance after the administration of antibiotics for at least three months, or the development of antibiotic resistance within at least three months of antibiotic administration. We planned to only evaluate resistance to the antibiotic(s) being investigated.

3. Serious adverse events.

\section{Secondary outcomes}

1. Health-related quality of life using measures validated in a clinical setting (e.g. SGRQ, Leicester Cough Questionnaire (LCQ), Quality of Life-Bronchiectasis (QoL-B) questionnaire).

2. Hospital admissions due to exacerbations (frequency, duration), defined using study authors' criteria.

3. Mortality (we planned to extract and report whether mortality is defined as all-cause or bronchiectasis-related in the individual studies).

4. Sputum volume and colour.

5. Symptoms (cough, dyspnoea, wheeze).

6. Lung function measured as forced expiratory volume in one second $\left(\mathrm{FEV}_{1}\right)$ (litres or per cent of predicted).

7. Exercise capacity (e.g. Six-Minute Walk Test or Incremental Shuttle Walk Test).

8. Adverse events/side effects.

We planned to use the definitions from Edwards 2000 and Hansen 2015 for serious adverse events and adverse events as follows.

1. Serious adverse events are those that result in death or life-threatening events; requirement for hospitalisation or prolongation of existing hospitalisation; persistent or significant disability; or congenital anomalies; or are events considered medically important.

2. Adverse events are any untoward occurrence that presents while a patient is taking a drug but does not necessarily have a causal relation to the treatment. They are undetectable by the patient; usually identified by laboratory tests (e.g. biochemical, haematological, immunological, radiological, and pathological tests); or by clinical investigations (e.g. gastrointestinal endoscopy, cardiac catheterisation).

Reporting one or more of the outcomes listed here in the study was not an inclusion criterion for the review.

\section{Search methods for identification of studies}

\section{Electronic searches}

We identified studies from the Cochrane Airways Group Register of Trials, which is maintained by the Information Specialist for the Group. The Cochrane Airways Trials Register contains studies identified from several sources, as follows.

1. Monthly searches of the Cochrane Central Register of Controlled Trials (CENTRAL, in the Cochrane Library), through the Cochrane Register of Studies Online (crso.cochrane.org);

2. Weekly searches of MEDLINE Ovid SP 1946 to date;

3. Weekly searches of Embase Ovid SP 1974 to date;

4. Monthly searches of PsycINFO Ovid SP;

5. Monthly searches of CINAHL EBSCO (Cumulative Index to Nursing and Allied Health Literature);

6. Monthly searches of AMED EBSCO (Allied and Complementary Medicine); and

7. Handsearches of the proceedings of major respiratory conferences.

We identified studies contained in the Trials Register through search strategies based on the scope of the Cochrane Airways Group. Details of these strategies, as well as a list of handsearched conference proceedings, are in Appendix 1. See Appendix 2 for search terms used to identify studies for this review.

We searched the following trials registries.

1. US National Institutes of Health Ongoing Trials Register ClinicalTrials.gov (www.ClinicalTrials.gov);

2. World Health Organization International Clinical Trials Registry Platform (apps.who.int/trialsearch).

We searched the Cochrane Airways Trials Register and additional sources from inception to 1 August 2017 and registries on 25 September 2017, with no restriction on language of publication.

\section{Searching other resources}

We checked the reference lists of all primary studies and review articles for additional references. We searched relevant manufacturers' websites for study information.

We planned to search for errata or retractions from included studies published in full text on PubMed and to report the date this was done within the review.

\section{Data collection and analysis}

\section{Selection of studies}

Two review authors (SM and TD) independently screened the titles and abstracts of the search results and coded them as 'retrieve' (eligible or potentially eligible/unclear) or 'do not retrieve'. We retrieved the full-text study reports of all potentially eligible studies and two review authors (SM and TD) independently screened them for inclusion, recording the reasons for exclusion 
of ineligible studies. We resolved disagreement through discussion or, if it had been necessary, we planned to consult a third review author (JC). We identified and excluded duplicates and collated multiple reports of the same study so that each study, rather than each report, was the unit of interest in the review. We recorded the selection process in sufficient detail to complete a PRISMA flow diagram and 'Characteristics of excluded studies' table (Moher 2009).

\section{Data extraction and management}

We planned to use a data collection form for study characteristics and outcome data, that had been piloted on at least one study in the review. One review author (TD) would have extracted the following study characteristics from included studies.

1. Methods: study design, total duration of study, details of any 'run-in' period, number of study centres and location, study setting, withdrawals and date of study.

2. Participants: N, mean age, age range, gender, severity of condition, diagnostic criteria, baseline lung function, smoking history, inclusion criteria and exclusion criteria.

3. Interventions: intervention, comparison, concomitant medications and excluded medications.

4. Outcomes: primary and secondary outcomes specified and collected, and time points reported.

5. Notes: funding for studies and notable conflicts of interest of trial authors.

We planned for two review authors (TD and LF) to independently extract outcome data from included studies. We planned to note in the 'Characteristics of included studies' table where outcome data were not reported in a usable way. We planned to resolve disagreements by consensus or by involving a third review author (JC). We also planned for one review author (TD) to transfer data into the Review Manager 5 file (Review Manager 2014); and to double-check that data were entered correctly by comparing the systematic review with the study reports. We planned for a second review author (LF) to spot-check study characteristics for accuracy against the study report.

\section{Assessment of risk of bias in included studies}

We planned for two review authors (LF and TD) to independently assess risk of bias for each study using the criteria outlined in the Cochrane Handbook for Systematic Reviews of Interventions (Higgins 2011); and to resolve disagreements by discussion or by involving another author (SM). We planned to assess the risk of bias according to the following domains.

1. Random sequence generation.

2. Allocation concealment.

3. Blinding of participants and personnel.

4. Blinding of outcome assessment.

5. Incomplete outcome data.

6. Selective outcome reporting.

7. Other bias.

We planned to judge each potential source of bias as high, low or unclear and provide a quote from the study report together with a justification for our judgement in the 'Risk of bias' table. We also planned to summarise the risk of bias judgements across different studies for each of the domains listed. We planned to consider blinding separately for different key outcomes where necessary (e.g. for unblinded outcome assessment, risk of bias for all-cause mortality may be very different than for a patient-reported pain scale). Where information on risk of bias related to unpublished data or correspondence with a trialist, we planned to note this in the 'Risk of bias' table.

When considering treatment effects, we planned to take into account the risk of bias for the studies that contributed to that outcome.

\section{Assessment of bias in conducting the systematic review}

We conducted the review according to the published protocol and planned to justify any deviations from it in the 'Differences between protocol and review' section of the systematic review.

\section{Measures of treatment effect}

We planned to analyse dichotomous data as odds ratios, and continuous data as mean differences or standardised mean differences. We planned to enter data presented as a scale with a consistent direction of effect.

We planned to undertake meta-analyses only when it was meaningful (i.e. when treatments, participants and the underlying clinical question were similar enough for pooling to make sense).

We planned to narratively describe skewed data reported as medians and interquartile ranges.

If multiple trial arms had been reported in a single trial, we planned to include only the relevant arms. If two comparisons (e.g. drug A versus placebo and drug $B$ versus placebo) had been combined in the same meta-analysis, we planned to halve the control group to avoid double-counting.

\section{Unit of analysis issues}

If we had included any studies, the unit of analysis would have been the participant. In terms of exacerbation rates and hospitalisation rates, we planned to focus on the number of events experienced by the participant during the trial and to analyse the results using rate ratios if possible. We planned to use adjusted data where it was available (e.g. rate ratios from Poisson regression models, or mean differences from ANOVA or results from cluster randomised studies adjusted for cluster effect) as a first choice, followed by change scores and final scores as last choice.

\section{Dealing with missing data}

We planned to contact investigators or study sponsors in order to verify key study characteristics and to obtain missing numerical outcome data where possible (e.g. when a study was only identified as an abstract). Where this was not possible, and missing data were thought to introduce serious bias, we planned to take this into consideration in the GRADE rating for affected outcomes.

\section{Assessment of heterogeneity}

We planned to use the $\mathrm{I}^{2}$ statistic to measure heterogeneity among the studies in each analysis; and if we had identified substantial heterogeneity, to report it and explore possible causes using the prespecified subgroup analyses. 


\section{Assessment of reporting biases}

If we had been able to pool more than 10 studies, we would have created and examined a funnel plot to explore possible small-study and publication biases.

\section{Data synthesis}

We planned to conduct meta-analyses when the population, interventions, outcomes and study designs were similar. In the presence of substantial heterogeneity $(>50 \%)$, we planned to report outcomes in the text, giving direction and size of the effect along with the strength of the evidence (risk of bias). We envisaged that antibiotic studies would vary by population, design, and outcomes, and therefore meta-analysis using a random-effects model would be most appropriate. However, where there are few studies or the effects of interventions across studies are not randomly distributed (e.g. with publication bias), the estimates from a random-effects model may be unreliable or biased. It was likely that this review would only include a small number of low-powered studies, and we had therefore planned to use a fixed-effect model, reported with 95\% confidence intervals $(\mathrm{Cl})$, and to evaluate the impact of model choice using a sensitivity analysis. We planned to synthesise and report dichotomous and continuous data separately for each outcome (e.g. exacerbation/ no exacerbation or exacerbation duration). Where end-of-study point estimates and change from baseline scores were reported, we planned to analyse these separately. Furthermore, we planned to use standardised mean differences (SMD) when outcomes were measured using different scales (e.g. health-related quality of life measures) and to use the baseline standard deviation (SD) for SMD analyses.

\section{'Summary of findings' table}

We planned to create a 'Summary of findings' table using the following outcomes: exacerbations; antibiotic resistance; serious adverse events; hospitalisations; mortality; symptoms; and quality of life. We planned to use the five GRADE considerations (risk of bias, consistency of effect, imprecision, indirectness and publication bias) to assess the overall quality of the evidence in terms of the studies that contributed data to the prespecified outcomes. We planned to use the methods and recommendations described in Section 8.5 and Chapter 12 of the Cochrane Handbook for Systematic Reviews of Interventions (Higgins 2011), using GRADEpro software (GRADEpro GDT); and to justify all decisions to downgrade the quality of studies using footnotes. We planned to include comments to aid the reader's understanding of the review where necessary.

\section{Subgroup analysis and investigation of heterogeneity}

We planned to carry out the following subgroup analyses.

1. Mode of delivery (e.g. oral, nebulised).

2. Antibiotic class (e.g. macrolide).

3. Duration participants colonised with $P$ aeruginosa.

4. Specifically for the outcome antibiotic resistance, we planned subgroup analyses according to the definition of antibiotic resistance (presence of antibiotic resistance versus development of antibiotic resistance, following at least three months' administration of antibiotics).

We planned to use the following outcomes in subgroup analyses.

1. Exacerbations.

2. Antibiotic resistance.

3. Serious adverse events.

We planned to use the formal test for subgroup interactions in Review Manager 5 (Review Manager 2014).

\section{Sensitivity analysis}

We planned to evaluate the impact of methodological quality using the following domains to remove studies at high or unclear risk of bias.

1. Random sequence generation.

2. Allocation concealment.

We planned to compare the results from a fixed-effect model with the random-effects model.

\section{RE S U L T S}

\section{Description of studies}

\section{Results of the search}

We identified 268 study reports in our database searches on 1 August and 25 September 2017, and 4 May 2018. We also searched the USA National Institutes of Health Ongoing Trials Register (www.ClinicalTrials.gov), the World Health Organization International Clinical Trials Registry Platform (apps.who.int/ trialsearch), conference proceedings and the reference lists of existing systematic reviews. We identified 13 additional records through other sources (WHO trials portal) but they were not relevant to our inclusion criteria Figure 1 
Figure 1. Study flow diagram.

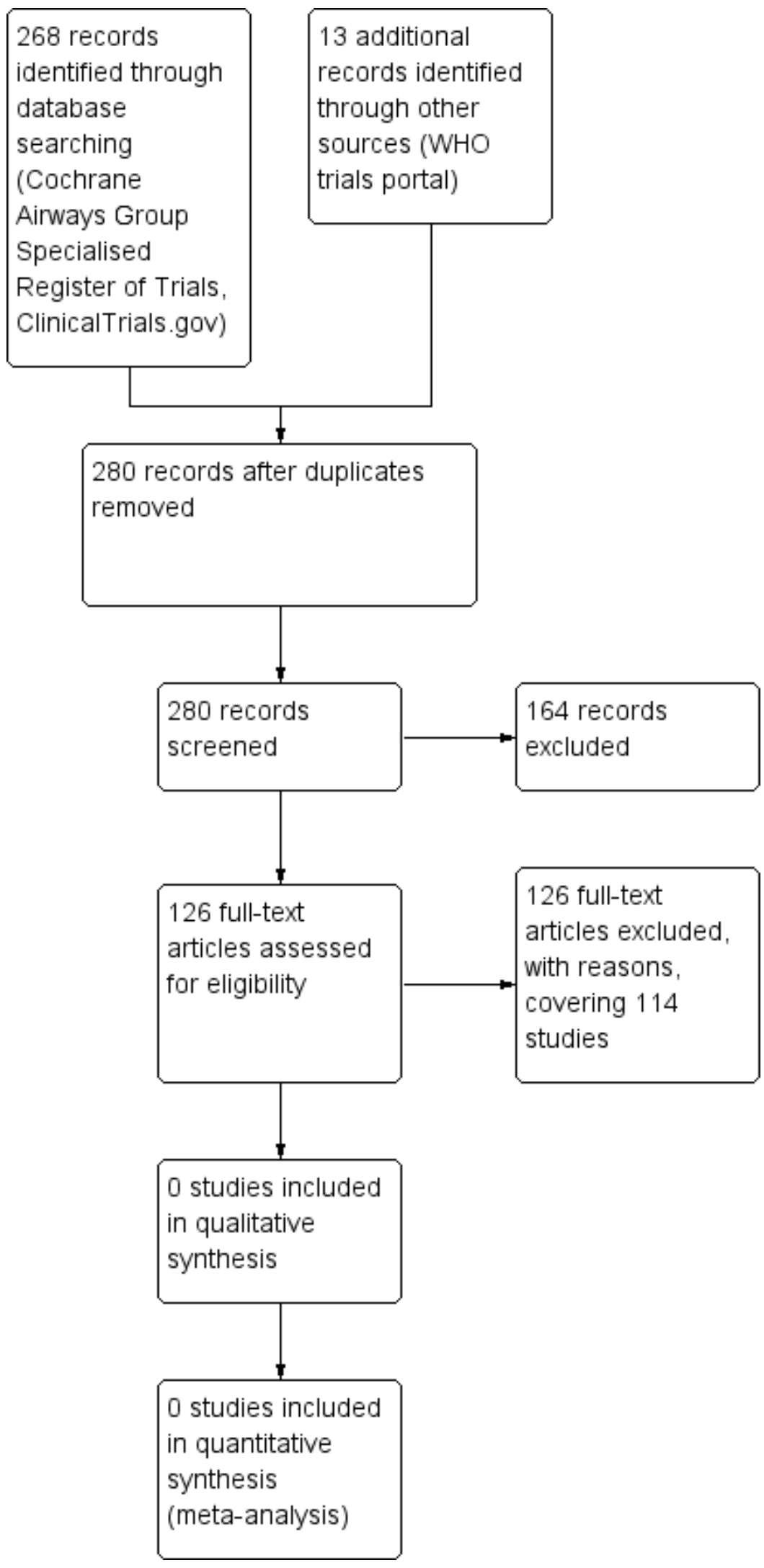




\section{Included studies}

We did not identify any studies relevant to our inclusion criteria.

\section{Excluded studies}

One hundred and twenty-six study reports (covering 114 studies) were excluded, with reasons, from original database searches following inspection of the study report (Characteristics of excluded studies). Sixty-seven (59\%) were not randomised studies (and were also otherwise not relevant to our inclusion criteria), 23 $(20 \%)$ compared an antibiotic versus placebo, $12(10 \%)$ compared different antibiotics, five (4\%) made a comparison between doses of the same antibiotic, two (2\%) were excluded on the basis of the study having no relevance to the condition. The following were also excluded: Juqin mixture (Chinese medicine) aerosol inhalation plus standard care versus standard care alone, one (1\%); comparison between Pidotimod versus no treatment, one (1\%); comparison between herbal decoction with standard decoction, one (1\%); comparison between colistimethate sodium versus saline solution, one (1\%); and the one remaining record $(1 \%)$ was a letter.

\section{Risk of bias in included studies}

No studies met the review inclusion criteria (Criteria for considering studies for this review). We were therefore unable to conduct the planned assessment risk of bias.

\section{Effects of interventions}

We were unable to evaluate the effectiveness of continuous versus intermittent antibiotics for bronchiectasis given the absence of studies meeting our inclusion criteria.

\section{DISCUSSION}

\section{Summary of main results}

We planned to evaluate the effectiveness of continuous versus intermittent antibiotics for bronchiectasis with respect to our predefined outcomes. Despite a comprehensive search, we identified no randomised trials meeting our predefined inclusion criteria (Criteria for considering studies for this review), revealing a paucity of evidence in this area.

\section{Overall completeness and applicability of evidence}

We were unable to assess completeness and applicability of evidence as no studies met our inclusion criteria.

\section{Quality of the evidence}

We were unable to consider the quality of the evidence as no studies were included in this review.

\section{Potential biases in the review process}

We carried out an extensive and comprehensive search for relevant studies, with expert support from the Cochrane Airways Group. We conducted searches in nine databases, and obtained translation of all potentially relevant non-English publications identified in our searches.

\section{Agreements and disagreements with other studies or reviews}

Although no other relevant systematic reviews or clinical trials were identified in our searches, in clinical practice both continuous and intermittent antibiotic administration is used with competing rationale (Chalmers 2015). Intermittent antibiotic treatment may help to limit resistance, because although antibiotics select for resistant bacteria, resistance often carries a 'fitness cost' for bacteria, meaning that resistant organisms are then overgrown once antibiotics are discontinued (Melnyk 2015). This is the reason that inhaled antibiotics are often administered in 28-day cycles with 28 days off between cycles. Two trials of aztreonam lysine have been performed using an intermittent regime in bronchiectasis (Barker 2014), while many antibiotics including tobramycin and aztreonam in cystic fibrosis are administered intermittently (Elborn 2016). In a network meta-analysis continuous administration of inhaled colistin was indirectly compared to intermittent administration of inhaled tobramycin and aztreonam for patients with cystic fibrosis and pseudomonas infection. Comparable efficacies were found between these arms, however their results are limited by a small overall study population and heterogeneity (Littlewood 2012). Evidence that this approach limits resistance in bronchiectasis is lacking. An added benefit of intermittent administration for inhaled antibiotics is that inhaled antibiotic therapy can take a long time to deliver, and so less frequent administration can improve compliance (McCullough 2014). Some preparations are also expensive and therefore intermittent administration may limit costs. For oral antibiotic administration, some studies suggest that bronchiectasis exacerbations are seasonal; for example Bibby and colleagues showed that admissions for bronchiectasis were more frequent in the winter and spring (Bibby 2015). Therefore it is common practice in some countries to give prophylactic antibiotics only during the winter.

Conversely, the argument in favour of continuous administration of antibiotics is that airway bacterial load, which is suppressed by antibiotics, rebounds back to baseline levels after approximately 14 days of antibiotic discontinuation, and this provokes increased airway inflammation (Chalmers 2012; Wilson 2013). Studies of azithromycin and nebulized gentamicin have shown that treatment benefit is lost once the drug is discontinued, although follow-up in both studies was only three months.(Murray 2011; Altenburg 2013).

\section{AUTHORS' CONCLUSIONS}

\section{Implications for practice}

Our review revealed a lack of relevant high-quality evidence, as thorough systematic searches failed to yield any randomised controlled trials comparing continuous versus intermittent prophylactic antibiotic administration for bronchiectasis.

Due to lack of scientific evidence on the comparative risks and benefits of continuous versus intermittent antibiotics for this population, British, European and Spanish guidelines have made recommendations based on the available literature, which at the moment are the only available guide for the management of patients with bronchiectasis (Pasteur 2010; Polverino 2017; Martínez-García 2018). For example, the European guidelines recommend long-term antibiotics for people with three or more 
exacerbations per year but make no recommendations regarding a continuous or intermittent therapeutic regime (Polverino 2017).

\section{Implications for research}

Although cystic fibrosis research may provide some insight it is likely bronchiectasis has different patterns of efficacy and particularly antibiotic resistance for continuous or intermittent antibiotics. They are different clinical entities and a direct extrapolation of clinical beneficial treatments in cystic fibrosis may not apply to bronchiectasis (Barker 2014). In identifying the most important research priorities for bronchiectasis, the European Bronchiectasis Network (EMBARC) reported the following as a key research question: "Studies should ideally evaluate whether cyclic or continuous administration of long-term antibiotics is superior both in terms of clinical efficacy and the emergence of resistance" (Aliberti 2016). This question is important because long-term antibiotic prophylaxis is widely used, and resolving this question has important implications for both efficacy and antibiotic resistance. Our review identified no studies that could answer this question.

It is evident that there is urgent need for robust randomised trials to evaluate continuous versus intermittent antibiotics for bronchiectasis with respect to: exacerbations (frequency, proportion with one or more, duration, time to next exacerbation) ideally defined using a new international consensus definition (Hill 2017); antibiotic resistance (defined as either the presence of antibiotic resistance after the administration of antibiotics for at least three months, or the development of antibiotic resistance within at least three months of antibiotic administration); and serious adverse events.

Similarly, consideration of the benefits of continuous versus intermittent antibiotics with respect to the following outcomes would also be especially helpful: health-related quality of life using measures validated in a clinical setting (e.g. SGRQ, LCQ, QoLB); hospital admissions due to exacerbations (both in terms of frequency and duration); mortality; sputum volume and colour; symptoms (cough, dyspnoea, wheeze); lung function measured as forced expiratory volume in one second $\left(\mathrm{FEV}_{1}\right)$; exercise capacity (e.g. Six-Minute Walk Test); and adverse events/side effects.

\section{ACKNOWLEDGEMENTS}

We would like to thank Edge Hill University for supporting this study. We would also like to thank the Cochrane Airways Group for its support.

We would especially like to thank Dr Chris Cates for his support; Chris was the Editor for this review and provided helpful, critical comments on the review and guidance. We would also particularly like to thank Emma Dennett, Liz Stovold, Emma Jackson and Rebecca Normansell.

We are most grateful to the following with the translation of nonEnglish study reports: Usama Al-Sari, Adelina Angusheva-Tihanov, Paul Ashton, Romain Bardot, Jane Dennis, Sylvia Ellis, Guillermo Guerra, Akira Kuriyama, Michela Masci, Georgi Popivanov, Laura Sansum, Marion Schulze, Birgit Smith, Daichi Suzuki and Joana Terzieva

The Background and Methods sections of this protocol are based on a standard template used by Cochrane Airways.

This project was supported by the National Institute for Health Research, via Cochrane Infrastructure funding to Cochrane Airways. The views and opinions expressed herein are those of the authors and do not necessarily reflect those of the Systematic Reviews Programme, NIHR, NHS or the Department of Health. 


\section{RE F E R E N C E S}

\section{References to studies excluded from this review}

Aksamit 2016 \{published data only\}

Aksamit TR, De Soyza A, Operschall E, Bandel T-J, Krahn U, Montegriffo $E$, et al. Baseline demographic profile of subjects of the phase 3 RESPIRE 2 trial of ciprofloxacin dry powder for inhalation (DPI) in non-cystic fibrosis bronchiectasis (NCFB). American Journal of Respiratory and Critical Care Medicine 2016;193:A1768

\section{Aksamit 2017 \{published data only\}}

Aksamit T, Bandel TJ, Criollo M, De Soyza A, Elborn JS, Operschall E, et al. The RESPIRE trials: two phase III, randomized, multicentre, placebo-controlled trials of ciprofloxacin dry powder for inhalation (ciprofloxacin dpi) in non-cystic fibrosis bronchiectasis. Contemporary Clinical Trials 2017; Vol. 58:78-85.

Aksamit TR, Bandel T-J, Criollo M, Elborn JS, Lau M, Operschall E, et al. Respire 2: ciprofloxacin dpi $32.5 \mathrm{mg}$ b.i.d. administered 14 days on/off or 28 days on/off vs. placebo for 48 weeks in patients with non-cystic fibrosis bronchiectasis (NCFB). American Journal of Respiratory and Critical Care Medicine 2017;195:A7642.

De Soyza A, Aksamit T, Operschall E, Bandel T-J, Krahn U, Criollo $M$, et al. Baseline demographic profile of subjects of the phase 3 RESPIRE 1 trial of ciprofloxacin dry powder for inhalation (DPI) in non-cystic fibrosis bronchiectasis (NCFB). European Respiratory Journal 2015;46:PA2617.

De Soyza A, Aksamit TR, Bandel T-J, Criollo M, Elborn JS, Krahn U, et al. RESPIRE 1: ciprofloxacin DPI 32.5mg b.d. administered 14 day on/off or 28 day on/off vs placebo for 48 weeks in subjects with non-cystic fibrosis bronchiectasis (NCFB). European Respiratory Journal 2016;48:0A272.

NCT01764841. Ciprofloxacin dry powder for inhalation in non-cystic fibrosis bronchiectasis (non-cf BE) [Randomized, double-blind, placebo-controlled, multicenter study comparing ciprofloxacin dpi $32.5 \mathrm{mg}$ bid (twice a day) intermittently administered for 28 days on / 28 days off or 14 days on / 14 days off versus placebo to evaluate the time to first pulmonary exacerbation and frequency of exacerbations in subjects with non-cystic fibrosis bronchiectasis]. clinicaltrials.gov/ct2/show/ NCT01764841 (first received 10 January 2013).

NCT02106832. Ciprofloxacin dry powder for inhalation (dpi) in non-cystic fibrosis bronchiectasis (non-CF BE) (RESPIRE 2) [Randomized, double-blind, placebo-controlled, multicenter study comparing ciprofloxacin dpi $32.5 \mathrm{mg}$ bid (twice a day) intermittently administered for 28 days on / 28 days off or 14 days on / 14 days off versus placebo to evaluate the time to first pulmonary exacerbation and frequency of exacerbations in subjects with non-cystic fibrosis bronchiectasis]. clinicaltrials.gov/ct2/show/NCT02106832 (first received 8 April 2014).

Quittner A, De Soyza A, Aksamit TR, Bandel T-J, Criollo M, Elborn JS, et al. Effects of ciprofloxacin dry powder for inhalation (ciprofloxacin DPI) on health-related quality of life in patients with non-cystic fibrosis bronchiectasis (NCFB): results from the Phase III RESPIRE 1 study. American Journal of Respiratory and Critical Care Medicine 2017;195:A7303.

\section{Alberto 1968 \{published data only\}}

Alberto S, Colongo PG, Brusasco L, Frigerio G. Studies of the clinical and respiratory functional effects of a mucolyticantibiotic preparation in chronic bronchopulmonary diseases. Controlled double-blind single code studies. Minerva Medica 1968;59(53):2995-3002.

\section{Alekseenko 1978 \{published data only\}}

Alekseenko AV, Sokolov SB, Kobrin LI, Opalinskii VN, Lavrent'ev luA. Direct current in the overall treatment of inflammatory suppurative diseases of the lungs [Voprosy Kurortologii, Fizioterapii, i Lechebonoi]. Fizicheskoi Kultury 1978;2:44-6.

\section{Alekseenko 1980 \{published data only\}}

Alekseenko AV. Effectiveness of conservative treatment of disseminated forms of chronic inflammatory-suppurative lung diseases. Terapevticheskii Arkhiv 1980;52(1):57-9.

\section{Aliberti 2016 \{published data only\}}

Aliberti S, Masefield S, Polverino E, De Soyza A, Loebinger MR, Menendez R, et al. Research priorities in bronchiectasis: a consensus statement from the EMBARC Clinical Research Collaboration. European Respiratory Journal 2016;48(3):632-47. [PUBMED: 27288031]

\section{Al-Mobeireek 1998 \{published data only\}}

Al-Mobeireek A, Kambal AM, Al-Balla SR, Al-Sawwaf H, Saleemi S. Pseudomonas aeruginosa in hospitalized patients with infective exacerbations of bronchiectasis: clinical and research implications. Annals of Saudi Medicine 1998;18(5):469-71.

\section{Antoniu 2013 \{published data only\}}

Antoniu S, Azoicai D. Ciprofloxacin dpi in non-cystic fibrosis bronchiectasis: a phase II randomized study. Expert Opinion on Investigational Drugs 2013;22(5):671-3.

\section{Cherniack 1959 \{published data only\}}

Cherniack NS, Vosti KL, Dowling HF, Lepper MH, Jackson GG. Long-term treatment of bronchiectasis and chronic bronchitis; a controlled study of the effects of tetracycline, penicillin, and an oleandomycinpenicillin mixture. Archives of Internal Medicine 1959;103(3):345-53.

\section{ChicTR-IOR-16008910 2016 \{published data only\}}

ChiCTR-IOR-16008910. Effectiveness of procalcitonin-guided antibiotic therapy in acute exacerbations of bronchiectasis: a randomized controlled trial. www.chictr.org.cn/ showprojen.aspx?proj=15079 (first received 26 July 2016).

\section{Chonabayasi 1988 \{published data only\}}

Chonabayasi N, Aosima M, Noguchi M, Yoshimura K, Nakatani T, Nakamori Y, et al. T-3262 in respiratory infections. Chemotherapy 1988; Vol. 36:439-53. 


\section{Choo 2018 \{published data only\}}

Choo JM, Abell GCJ, Thomson R, Morgan L, Waterer G, Gordon DL, et al. Impact of long-term erythromycin therapy on the oropharyngeal microbiome and resistance gene reservoir in non-cystic fibrosis bronchiectasis. $m S p h e r e$ 2018;3(2):e00103-18.

\section{Cseri 1975 \{published data only\}}

Cseri T, Kelemen S. Treatment with sumetrolim in chronic non-specific respiratory tract infections. Therapia Hungarica 1975;23(3):115-7.

\section{Currie 1987 \{published data only\}}

Currie DC, Garbett ND, Chan KL, Higgs E, Todd H, Nunn AJ, et al. Double blind randomised placebo controlled study of long term high dose antibiotic in patients with bronchiectasis [abstract]. Clinical Research 1987;72(s16):79P.

Currie DC, Gargett ND, Cole PJ. Penetration of antibiotics into the respiratory tract. British Medical Journal (Clinical Research Ed.) 1987;295(6590):119. [EMBASE: 10.1136/bmj.295.6590.119]

\section{Dimakou 2017 \{published data only\}}

Dimakou K, Kaponi M, Karampitsakos T, Tzouvelekis A, Chrysikos S, Melachroinidou M, et al. Eradication treatment in Non CF bronchiectasis: the effect of inhaled antibiotics (tobramycin and colistin) on patients with pseudomonas aeruginosa. European Respiratory Journal 2017;suppl 61:OA1971.

Dimakou K, Liapikou A, Triantafilidou C, Chrysikos S, Kaponi M, Melachroinidou M, et al. Non cf bronchiectasis: the effect of inhaled antibiotics (tobramycin and colistin) in patients with pseudomonas aeruginosa in sputum. American Journal of Respiratory and Critical Care Medicine 2017;195:A1518.

\section{Douglas 1957 \{published data only\}}

Douglas AC, Somner AR, Marks BL, Grant IWB. Effect of antibiotics on purulent sputum in chronic bronchitis and bronchiectasis. Lancet 1957;273(6988):214-8.

\section{Hayashi 1989 \{published data only\}}

Hayashi T, Yamada H, Yasuoka A, Sasayama K, Doutsu Y, Kohno S, et al. Basic and clinical studies on cefdinir. Chemotherapy 1989;37(Supplement 2):565-78.

\section{Hill 1992 \{published data only\}}

Hill SL, Bilton D, Johnson MM, Pye A, Mitchell JL, Stockley RA. Sputum and serum pharmacokinetics of loracarbef (a new carbacephem antibiotic) in patients with bronchiectasis [Abstract]. European Respiratory Journal 1992;5:142s.

\section{Howie 1976 \{published data only\}}

Howie JG. Antibiotics and purulent sputum. British Medical Journal 1976;2(6040):882.

\section{Huang 2018 \{published data only\}}

Huang H, Yang P, Wang J, Wu Y, Zi S, Tang J, et al. Investigation into the individualized treatment of traditional chinese medicine through a series of n-of-1 trials. Evidence- based Complementary and Alternative Medicine : ECAM 2018;2018:Article Number: 5813767.

Hughes 1973 \{published data only\}

Hughes DT. Use of combinations of trimethoprim and sulfamethoxazole in the treatment of chest infections. Journal of Infectious Diseases 1973;128(Suppl):701-5.

Hughes DT. Use of combinations of trimethoprim and sulphamethoxazole in the treatment of chest infections. Medical Journal of Australia 1973;1(2):58-61.

Iglauer 1973 \{published data only\}

Iglauer E, Wieser O. Parenteral treatment of severe bronchopulmonary infections using trimethoprim and sulfamethoxazole. Wiener Medizinische Wochenschrift (1946) 1973; Vol. 123, issue 20:322-3.

Inoue 1989 \{published data only\} Inoue Y, Masuyama Y, Dotsu Y, Kaku M, Suyama N, Hayashi T, et al. Basic and clinical studies on 7432-S. [Japanese]. Chemotherapy 1989;37:285-97.

Irabu 1989 \{published data only\}

Irabu Y, Tamaki K, Fukuhara H, Nakamura H, Kaneshima H, Shimoij K, et al. Laboratory and clinical studies on cefdinir. [Japanese]. Chemotherapy 1989;37:603-11.

Irabu 1992 \{published data only\}

Irabu Y, Fukuhara H, Nakamura H, Kaneshima H, Simoji K, Kitsukawa K, et al. Laboratory and clinical studies of ME1207. [Japanese]. Chemotherapy 1992;40:452-8.

Juthong 2011 \{published data only\} Juthong S, Eiamsa-ard S. The effects of roxithromycin as anti-inflammatory agent on clinical outcomes in patient with bronchiectasis: A double blinded randomized controlled study [Abstract]. European Respiratory Journal 2011;38:819s.

\section{Kanai 1963 \{published data only\}}

Kanai J, Tanaka S, Matsumoto T, Noda S. Clinical trial use of phenoxypropyl penicillin. Journal of Antibiotics 1963;16:25-6.

Kawano 1974 \{published data only\}

Kawano M, Irimajiri K, Higuchi J, Uchiyama T, Tsubura E. Studies on amikacin (BB-K8), a new aminoglycoside antibiotic (author's transl). Japanese Journal of Antibiotics 1974;27(4):446-50.

Kawashima 1989 \{published data only\}

Kawashima K, Yamamoto H, Kadoya M, Kato M, Nata T, lida E, et al. Clinical role of Branhamella catarrhalis infection in pulmonary disorders. [Japanese]. Saishin Igaku [Modern Medicine] 1989;44(6):1268-72.

Koyama 1992 \{published data only\} Koyama M. ME1207: a clinical study. [Japanese]. Chemotherapy 1992;40:692-5.

Krawczyk 1981 \{published data only\}

Krawczyk Z, Gornicka Wilczynska M, Pilarska Machowicz A, Pruszynska S. Comparative evaluation of certain antibiotics 
and Biceptol preparation in the treatment of chronic bronchial disease exacerbations. [Polish]. Polski Tygodnik Lekarski 1981;36(25):927-30.

\section{Kudo 1992 \{published data only\}}

Kudo K, Ishii A, Kabe J. ME1207 in respiratory infections. [Japanese]. Chemotherapy 1992;40:696-9.

\section{Kurishima 1992 \{published data only\}}

Kurishima S, Hirose H, Fukui T, Katsu M. Basic and clinical studies on cefclidin. [Japanese]. Chemotherapy 1992;40:273-9.

\section{Kuze 1988 \{published data only\}}

Kuze F, Kurasawa T, Kato M, Kagioka A, Inaba N, Kuroda N, et al. Cefodizime (THR-221) in respiratory tract infections. [Japanese]. Chemotherapy 1988;36:467-72.

\section{Lamotte 1981 \{published data only\}}

Lamotte A. Bronchiectasis [French]. Ouest-medical 1981;34(14):969-72.

\section{Ledson 2000 \{published data only\}}

Ledson MJ, Cowperthwaite C, Walshaw MJ, Gallagher MJ, Williets T, Hart CA. Nebulised taurolidine and B cepacia bronchiectasis. Thorax 2000;55(1):91-2.

\section{Lunacharskaia 1968 \{published data only\}}

Lunacharskaia TV, Kopeiko IP. Intratracheal use of morphocycline. [Russian]. Antibiotiki 1968;13(12):1123-6.

\section{Maekawa 1967 \{published data only\}}

Maekawa N, Tsukuma S, Nakanishi M, Yamashita M, Kanda M. Clinical results of the use of cephaloridine in lung diseases, especially pulmonary tuberculosis. [Japanese]. Journal of Antibiotics. Ser. B 1967;20(2):140-4.

\section{Masuno 1992 \{published data only\}}

Masuno T, Ikeda T, Kishimoto S, Morimoto Y, Tsujimoto T, Igarashi T, et al. A clinical study of cefclidin. Chemotherapy 1992;40:331-40.

\section{Matsumoto 1984 \{published data only\}}

Matsumoto K, Nagatake T, Shishido H. Laboratory and clinical evaluation of lenampicillin (KBT-1585) in respiratory infection. [Japanese]. Chemotherapy 1984;32:397-411.

\section{Matsumoto 1992 \{published data only\}}

Matsumoto M, Koga Y, Ando M, Araki S. Clinical studies on ME1207 in the treatment of respiratory tract infections. [Japanese]. Chemotherapy 1992;40:740-3.

\section{Matsuura 1993 \{published data only\}}

Matsuura T, Suzuki K, Yamamoto T. Clinical studies of S-1108 in elderly patients. Chemotherapy 1993;41:795-9.

\section{May 1974 \{published data only\}}

May JR, Ingold H. Amoxicillin in the treatment of lower respiratory infections. Advances in Clinical Pharmacology 1974;7:85-90.

\section{Mazzei 1993 \{published data only\}}

Mazzei JA, Vujacich P, Fernandez A, Tanco J. Ciprofloxacin in the treatment of lower respiratory tract infections. Drugs 1993;46:407-9.

\section{Messens 1973 \{published data only\}}

Messens Y, Oger A, Cornette M, Calay G. Double-blind study of the sulfamethoxazole-trimethoprim association in the treatment of pulmonary infections. Acta Clinica Belgica 1973;28(2):92-9.

\section{Milcev 1985 \{published data only\}}

Milcev M, Ovcarova H, Ivanov S. Antibacterial treatment of anaerobic lung infections. [Bulgarian]. Pnevmologiya i Ftiziatriya 1985;22(3):20-4.

Ming 2005 \{published data only\}

Ming O, Yong Li, Zhang W. Efficacy of macrolide and theophylline in the management of bronchiectasis. Respirology 2005;10:A168.

\section{Molodtsova 1980 \{published data only\}}

Molodtsova VP, Fedoseev GB, Gerasin VA. Cleansing of the bronchial tree in treating chronic inflammatory lung diseases. [Russian]. Sovetskaia Meditsina 1980;11(11):90-2.

\section{Morrone 1989 \{published data only\}}

Morrone N, Saito M, Brito VC, Hayashi F. Pulmonary infections in adults: two therapeutics regimens of ofloxacin. Folha Medica 1989;98(4):253-8.

\section{Murayama 1992 \{published data only\}}

Murayama T, Kuze F, Oida K, Nanbu Y, Iwata T, Ikeda N, et al. A clinical study of the effects of ME1207 on respiratory infections [Japanese]. Chemotherapy 1992;40:724-7.

\section{Nagy 1968 \{published data only\}}

Nagy M, Meszaros G. Late results of the conservative treatment of bronchiectasis in adults. [German]. Zeitschrift fur Tuberkulose und Erkrankungen der Thoraxorgane 1968;127(5):283-90.

Nakagawa 1989 \{published data only\}

Nakagawa Y, Niki Y, Hino J, Kishimoto T, Kawane H, Soejima R. Bacteriological and clinical studies of cefdinir. Chemotherapy 1989; Vol. 37:518-24.

Nakagawa 1993 \{published data only\}

Nakagawa M, Tsubura E. Clinical study of S-1108 in respiratory infections. Chemotherapy 1993;41:803-6.

Nasu 1988 \{published data only\}

Nasu M, Yamazaki T, Yamazaki H, Kuroda Y, Goto Y, Shigeno H, et al. T-3262 in respiratory tract infections [Japanese]. Chemotherapy 1988;36:699-709.

NCT00415350 \{published data only\}

NCT00415350. Bronchiectasis and long term azithromycin treatment [Bronchiectasis and long term azithromycin treatment: a randomised placebo-controlled trial studying disease modifying effects of immunomodulating treatment]. 
clinicaltrials.gov/ct2/show/NCT00415350 (first received 22 December 2006)

\section{NCT00524095 \{published data only\}}

NCT00524095. Bronchiectasis in chronic obstructive pulmonary disease (COPD) patients: role of prophylaxis [Bronchiectasis in COPD patients : role of prophylaxis with inhaled steroids and antibiotic on the natural history of the disease]. clinicaltrials.gov/ct2/show/NCT00524095 (first received 3 September 2007).

\section{NCT00775138 \{published data only\}}

NCT00775138. A study to determine the safety and tolerability of arikace versus placebo in patients who have bronchiectasis [A placebo controlled, randomized, parallel cohort, safety and tolerability study of 2 dose levels of liposomal amikacin for inhalation (Arikace ${ }^{\mathrm{TM}}$ ) in patients with bronchiectasis complicated by chronic infection due to pseudomonas aeruginosa]. clinicaltrials.gov/ct2/show/NCT00775138 (first received 17 October 2008).

\section{NCT00889967 \{published data only\}}

NCT00889967. Safety and efficacy study of ciprofloxacin for inhalation in patients with non-cystic fibrosis bronchiectasis "ORBIT-1" [An international, multicenter, randomized, doubleblind, placebo-controlled study to evaluate the efficacy, safety, and tolerability of once daily administration of two strengths of ciprofloxacin for inhalation compared with placebo for inhalation in the management of pseudomonas aeruginosa in patients with non cystic fibrosis bronchiectasis]. clinicaltrials.gov/ct2/show/NCT00889967 (first received 29 April 2009).

\section{NCT00930982 \{published data only\}}

NCT00930982. Evaluation of cipro inhale in patients with noncystic fibrosis bronchiectasis [Randomized, placebo-controlled, double-blind, multi-center study to evaluate the safety and efficacy of ciprofloxacin inhale compared to placebo in patients with non-cystic fibrosis bronchiectasis]. clinicaltrials.gov/ct2/ show/NCT00930982 (first received 2 July 2009).

\section{NCT01313624 \{published data only\}}

NCT01313624. A study to see if AZLI (an inhaled antibiotic) is effective in treating adults with non-cf bronchiectasis - AIR-BX1 [A phase 3, double-blind, multicenter, randomized, placebocontrolled trial evaluating repeated courses of aztreonam for inhalation solution in subjects with non-cf bronchiectasis and gram-negative endobronchial infection]. clinicaltrials.gov/ct2/ show/NCT01313624 (first received 14 March 2011).

\section{NCT01515007 \{published data only\}}

NCT01515007. Phase 3 Study With Ciprofloxacin Dispersion for Inhalation in Non-CF Bronchiectasis (ORBIT-3). ClinicalTrials.gov 2012.

\section{NCT01538667 \{published data only\}}

NCT01538667. Study to characterize lung deposition, pharmacokinetics, safety and tolerability of single inhalations of radiolabeled ciprofloxacin dry powder in healthy subjects and patients with chronic lung diseases [Non-blinded, single dose, single centre trial to assess the pulmonary deposition as well as pharmacokinetics, safety and tolerability of $99 \mathrm{mTc}$ labeled ciprofloxacin when delivered as a single dose from a dry powder inhaler to healthy subjects with and without charcoal block and patients suffering from bronchiectasis and COPD]. clinicaltrials.gov/ct2/show/NCT01538667 (first received 24 February 2012).

\section{NCT01761214 \{published data only\}}

NCT01761214. Bacteriology and inflammation in bronchiectasis [Bacteriology and sputum and systemic inflammation in steadystate, acute exacerbation and recovery of bronchiectasis]. clinicaltrials.gov/ct2/show/NCT01761214 (first received 4 January 2013).

\section{NCT02035488 \{published data only\}}

NCT02035488. Pharmacokinetic evaluation and tolerability of dry powder tobramycin by a novel device in patients with non cystic fibrosis bronchiectasis. clinicaltrials.gov/ct2/show/ NCT02035488 (first received 14 January 2014).

\section{NCT02047773 \{published data only\}}

NCT02047773. Bacterial load guided therapy for severe bronchiectasis exacerbations [Bacterial load guided therapy for severe exacerbations of bronchiectasis requiring intravenous antibiotic therapy- BLT Br IV study]. clinicaltrials.gov/ct2/show/ NCT02047773 (first received 28 January 2014).

\section{NCT02081963 \{published data only\}}

NCT02081963. Combined administration of nebulized amikacin in patients with acute exacerbation of non-cystic fibrosis bronchiectasis [A randomized, controlled study of combined administration of nebulized amikacin in patients with acute exacerbation of non-cystic fibrosis bronchiectasis]. clinicaltrials.gov/ct2/show/NCT02081963 (first received 7 March 2014).

\section{NCT02102152 \{published data only\}}

NCT02102152. Efficacy \& tolerability of tobramycin podhaler in bronchiectasis patients with chronic pseudomonas aeruginosa infection. clinicaltrials.gov/ct2/show/NCT02102152 (first received 2 April 2014).

\section{NCT02104245 \{published data only\}}

NCT02104245. Phase 3 Study With Ciprofloxacin Dispersion for Inhalation in Non-CF Bronchiectasis (ORBIT-4). ClinicalTrials.gov 2014.

NCT02107274 \{published data only\}

NCT02107274. Efficacy of azithromycin in treatment of bronchiectasis. clinicaltrials.gov/ct2/show/NCT02107274 (first received 8 April 2014).

\section{NCT02315547 \{published data only\}}

NCT02315547. Sputum microbiota and the association with clinical parameters in steady-state, acute exacerbation and convalescence of bronchiectasis (BISER-2). clinicaltrials.gov/ ct2/show/NCT02315547 (first received 12 December 2014).

NCT02491723 \{published data only\}

NCT02491723. Macrolide mediates pulmonary infection of pseudomonas aeruginosa [Macrolide mediates pulmonary 
infection of pseudomonas aeruginosa via NLRC4 inflammasome signaling pathway]. clinicaltrials.gov/ct2/show/NCT02491723 (first received 8 July 2015).

\section{NCT02509091 \{published data only\}}

NCT02509091. Therapy of bronchoalveolar lavage and local amikacin injection in patients with acute exacerbation of bronchiectasis [Clinical efficacy and safety of therapy of bronchoalveolar lavage and local amikacin injection in patients with acute exacerbation of bronchiectasis:an open-label randomized parallel controlled study]. clinicaltrials.gov/ct2/ show/NCT02509091 (first received 27 July 2015).

\section{NCT02657473 \{published data only\}}

NCT02657473. Inhaled nebulized tobramycin in non-cystic fibrosis bronchiectasis (BATTLE) [Long-term inhaled nebulized tobramycin in patients with non-cystic fibrosis bronchiectasis. A randomized placebo controlled trial. The BATTLE study bronchiectasis and tobramycin solution inhalation therapy]. clinicaltrials.gov/ct2/show/NCT02657473 (first received 15 January 2016).

\section{NCT02661438 \{published data only\}}

NCT02661438. Summative usability study of ciprofloxacin dry powder for inhalation using placebo [Multicenter summative usability study of ciprofloxacin dry powder for inhalation in subjects with non-cystic fibrosis bronchiectasis (NCFB) or chronic obstructive pulmonary disease (COPD) using matching placebo]. clinicaltrials.gov/ct2/show/NCT02661438 (first received 22 January 2015).

\section{NCT03058718 \{published data only\}}

NCT03058718. Procalcitonin-guided antibiotic therapy in bronchiectasis [Effectiveness of procalcitonin-guided antibiotic therapy in acute exacerbations of bronchiectasis: a randomized controlled trial]. clinicaltrials.gov/ct2/show/NCT03058718 (first received 23 February 2017).

\section{NCT03093974 \{published data only\}}

NCT03093974. Trial in non-cystic fibrosis bronchiectasis patients with chronic lung infections treated with colistimethate sodium (PROMIS-I). clinicaltrials.gov/ct2/show/ NCT03093974 (first received 28 March 2017).

\section{NCT03460704 \{published data only\}}

Trial in non-cystic fibrosis bronchiectasis patients with chronic lung infections treated with colistimethate sodium (PROMIS-2). https://clinicaltrials.gov/show/NCT03460704.

\section{Neumayr 1963 \{published data only\}}

Neumayr A, Stoefler G. Clinical trials of the new antibiotic, rifamycin sv: preliminary report. Chemotherapy 1963;12:437-8.

\section{O'Donnell 2016 \{published data only\}}

O'Donnell AE, Bilton D, Serisier D, Wanner A, Froehlich J, Bruinenberg P, et al. ORBIT-3 and ORBIT-4: design of a phase 3 program to investigate safety and efficacy of pulmaquin in non-cystic fibrosis bronchiectasis (NCFBE) patients chronically colonized with pseudomonas aeruginosa (PA). American Journal of Respiratory and Critical Care Medicine 2016;193:A1775.
Obana 1992 \{published data only\}

Obana M, Matsuoka Y, Irimajiri S, Yoshioka I. Clinical study on ME1207 in respiratory tract infections. Chemotherapy 1992;40:700-2.

\section{Odagiri 1992 \{published data only\}}

Odagiri S, Suzuki K, Murohashi K, Takahashi H, Takahashi K. Clinical study of ME 1207 in respiratory tract infections. Chemotherapy 1992;40:703-7.

\section{Oizumi 1978 \{published data only\}}

Oizumi K, Watanabe A, Konno K, Hayashi I, Kawamorida K, Nagai K, et al. Therapeutic effect of amikacin for infections with gram-negative bacilli, especially for stubborn respiratory infections (author's transl). [Japanese]. Japanese Journal of Antibiotics 1978;31(1):15-23.

\section{Pezza 1983 \{published data only\}}

Pezza A, Giacomelli P, Montella R, Casino G. Clinical study of a new cephalosporin: ceftriaxone (RO 13-9904) in resurgent acute and chronic bronchopneumopathies. [Italian]. Archivio Monaldi per la Tisiologia e le Malattie dell'Apparato Respiratorio 1983;38(1):17-24.

\section{Rikitomi 1988 \{published data only\}}

Rikitomi N, Shishido H, Nagatake T, Mbaki U, Matsumoto K. Preclinical and clinical studies on TE-031 (A-56268) in treatment of bacterial respiratory tract infections. Chemotherapy 1988;36:715-28.

\section{Saito 1993 \{published data only\}}

Saito A, Kusano N, Fukuhara H, Soejima R, Nakahama C, Niki Y, et al. A study of the clinical effects of clindamycin on respiratory infections - Focusing on inhibition of beta-lactamase production. [Japanese]. Chemotherapy 1993;41(11):1232-45.

\section{Santiveri 1995 \{published data only\}}

Santiveri C, Orriols R, Roig J, Balcells E, Bellver P, Ferrer A, et al. Effectiveness of inhaled antibiotic treatment for pseudomonas aeruginosa in outpatients with colonized bronchiectasis without mucoviscidosis. Archivos de Bronconeumologia 1995;31:42.

\section{Schulz 1972 \{published data only\}}

Schulz G. Comparative studies on the toxicity of tetracyclines and chloramphenicol in the treatment of nonspecific bronchopulmonary infections. [German]. Zeitschrift fur Erkrankungen der Atmungsorgane Mit Folia Bronchologica 1972;136(2):185-96.

\section{Serisier 2011 \{published data only\}}

Serisier DJ, Thompson PJ, Greville H, Kolbe J, Bruinenberg PR. Dual release ciprofloxacin for inhalation (DRCFI) reduces sputum pseudomonas aeruginosa $(\mathrm{Pa})$ density and delays time to infective pulmonary exacerbation in non-cystic fibrosis (CF) bronchiectasis (BE) [Abstract]. European Respiratory Journal 2011;28:334s.

\section{Serisier 2012 \{published data only\}}

Burr LD, Rogers GB, Chen AC-H, Hamilton BR, Pool GF, Taylor SL, et al. Macrolide treatment inhibits pseudomonas aeruginosa 
quorum sensing in non-cystic fibrosis bronchiectasis: an analysis from the bronchiectasis and low-dose erythromycin study trial. Annals of the American Thoracic Society 2016;13:1697-1703.

Rogers GB, Bruce KD, Martin ML, Burr LD, Serisier DJ. Corrections to, The effect of long-term macrolide treatment on respiratory microbiota composition in non-cystic fibrosis bronchiectasis: an analysis from the randomised, double-blind, placebo-controlled BLESS trial. Lancet Respiratory Medicine 2015;3(4):e15. [DOI: 10.1016/S2213-2600(15)00102-2]

Serisier DJ, Bowler SD, McGuckin M, Chen A, Lourie R, Martin ML. The bronchiectasis and low-dose erythromycin study (BLESS) [Abstract]. American Journal of Respiratory and Critical Care Medicine 2012;185:A6862.

\section{Shigeno 1984 \{published data only\}}

Shigeno Y, Masaki M, Nakazato H. Laboratory and clinical studies on lenampicillin (KBT-1585) a new penicillin antibiotic. [Japanese]. Chemotherapy 1984;32:382-96.

Shimada 1988 \{published data only\}

Shimada K, Inamatsu T, Fukayama M, Kato A, Adachi K, Sasaki M, et al. Antimicrobial activity and clinical evaluation of NY-198. Chemotherapy 1988; Vol. 36:537-44.

\section{Shimokata 1992 \{published data only\}}

Shimokata K, Sakai S, Senda Y, Nishiwaki K, Yamaoto M, Murate $T$, et al. Evaluation of cefclidin on respiratory tract infections. Chemotherapy 1992;40:748-52.

\section{Shishido 1995 \{published data only\}}

Shishido H, Furukawa K, Nagai H, Kawakami K, Kono H. Oral levofloxacin $600 \mathrm{mg}$ and $300 \mathrm{mg}$ daily doses in difficult-to-treat respiratory infections. Drugs 1995;49:433-5.

\section{Simioli 2017 \{published data only\}}

Simioli F, Sorrentino N, Martino M, Porzio M, Stanziola AA, Molino A, et al. Open label case-control study to assess Pidotimod efficacy in Non CF Bronchiectasis Disease: a pilot study. European Respiratory Journal 2017;50:PA4063.

\section{Soejima 1988 \{published data only\}}

Soejima R, Niki Y, Hino J, Nakagawa Y, Sumi M, Kishimoto T, et al. Clinical studies on TE-031 (A-56268). Chemotherapy 1988;36:673-8

\section{Suga 1988 \{published data only\}}

Suga M, Ando M, Tanaka F, Ito K, Sakata T, Sugimoto M, et al. Clinical studies of T-3262 in respiratory tract infection. [Japanese]. Chemotherapy 1988;36:694-8.

\section{Sun 2015 \{published data only\}}

Sun JX, Xi MJ, Tu CL, Liu RR, Hu JR, Zhu LP. Efficacy of Juqin mixture aerosol inhalation treatment of bronchiectasis. Chinese Journal of Experimental Traditional Medical Formulae 2015;21:167-70.

\section{Suyama 1988 \{published data only\}}

Suyama N, Inoue Y, Masaki M, Mashimoto H, Masuyama Y, Dohtsu Y, et al. Laboratory and clinical studies on cefodizime (THR-221). Chemotherapy 1988;36:529-44.

Tagaya 2001 \{published data only\}

Tagaya E, Tamaoki A, Kondo M, Nakada J, Nagai A. Effect and action mechanism of short-term administration of clarithromycin for airway hypersecretion. [Japanese]. Japanese Journal of Antibiotics 2001;54:33-35.

\section{Tamura 1992 \{published data only\}}

Tamura S, Tokita K, Tsutsumi Z, Ohkawa T, Fujioka H, Kurabori J, et al. Clinical studies on cefclidin. Chemotherapy 1992;40:737-47.

Tanimoto 1992 \{published data only\}

Tanimoto H, Obara K, Komatuzaki K, Tanabe O, Okamura T. A clinical study on ME1207 in respiratory infections. Chemotherapy 1992;40:683-5.

Tanimoto 1993 \{published data only\} Tanimoto H, Obara K, Tateishi O, Okamura T. Clinical studies on S-1108 in respiratory infections. Chemotherapy 1993;41:751-4.

Twiss 2009 \{published data only\}

Twiss J, Byrnes C. Nebulised antibiotics reduce symptoms, bacterial density and oral antibiotic usage in children with non cystic fibrosis bronchiectasis [Abstract]. Respirology 2009;14:A76

Wada 1992 \{published data only\}

Wada K, Kawashima T, Tukada H, Igarashi K, Arakawa M. Clinical study of ME1207. Chemotherapy 1992;40:708-10.

Watanabe 1988 \{published data only\}

Watanabe K, Koyama M, Yokozawa M. Basic and clinical studies on cefotiam hexetil. Chemotherapy 1988;36:311-22.

Watanabe 1991 \{published data only\}

Watanabe A. Once daily versus every two week multidose ofloxacin in patients with acute exacerbations of chronic respiratory disease. Infection 1991;19:S384-7.

Watanabe 1995 \{published data only\}

Watanabe A, Oizumi K, Motomiya M, Nukiwa T. Daily single-dose regimen and alternate-two-week triple-dose/day regimen of oral ofloxacin for the prophylaxis and control of exacerbations of chronic respiratory tract infections. Tohoku Journal of Experimental Medicine 1995;176(1):25-33.

\section{Weston 1966 \{published data only\}}

Weston M. A clinical trial of fusafungin. British Journal of Diseases of the Chest 1966; Vol. 60, issue 2:104-6.

Wilson 2011 \{published data only\}

Wilson R, Welte T, Polverino E, De Soyza A, Greville HW, O'Donnell AE, et al. Efficacy and safety of ciprofloxacin dry powder for inhalation in patients with non-cystic fibrosis bronchiectasis [Abstract]. European Respiratory Journal 2011;38(55):334s. 
Wong 2004 \{published data only\}

Wong M, Lam J, Ip S, Lam CL, Tsang KW. Quality of life effect of levofloxacin compared to ceftazidime treatment in infective exacerbation of bronchiectasis [Abstract]. Respirology 2004;9:A135.

\section{Yamada 1993 \{published data only\}}

Yamada H, Katoh O, Aoki Y, Nakata H, Yamaguchi M. Clinical study on S-1108 in respiratory tract infections. Chemotherapy 1993;41:816-9.

\section{Yoshida 1989 \{published data only\}}

Yoshida T, Tao M, Tanaka H, Morito T, Nagatake T, Shishido H, et al. Basic and clinical evaluation of cefdinir, a new oral cephem. Chemotherapy 1989;37:579-90.

Zegaya 1981 \{published data only\}

Zegaya M, Belkahia Ch, Ladjimi S. Study of doxycycline in pleuropulmonary affections. La Tunisie Medicale 1981;59(5):401-7.

\section{References to ongoing studies}

NCT02712983 \{published data only\}

Dose-finding Study to Assess the Efficacy, Safety and Tolerability of Tobramycin Inhalation Powder in Patients With Non-Cystic Fibrosis Bronchiectasis and Pulmonary P. Aeruginosa Infection (iBEST-1). Ongoing study 2 February 2017.

\section{Additional references}

\section{Altenburg 2013}

Altenburg J, de Graaff CS, Stienstra Y, Sloos JH, van Haren EH, Koppers RJ, et al. Effect of azithromycin maintenance treatment on infectious exacerbations among patients with non-cystic fibrosis bronchiectasis: the BAT randomized controlled trial. JAMA 2013;309(12):1251-9. [PUBMED: 23532241]

\section{Barker 2014}

Barker AF, O'Donnell AE, Flume P, Thompson PJ, Ruzi JD, de Gracia J, et al. Aztreonam for inhalation solution in patients with non-cystic fibrosis bronchiectasis (AIR-BX1 and AIR-BX2): two randomised double-blind, placebo-controlled phase 3 trials. Lancet 2014;2(9):738-49. [PUBMED: 25154045]

\section{Bibby 2015}

Bibby S, Milne R, Beasley R. Hospital admissions for non-cystic fibrosis bronchiectasis in New Zealand. New Zealand Medical Journal 2015;128(1421):30-8.

\section{Brodt 2014}

Brodt AM, Stovold E, Zhang L. Inhaled antibiotics for stable noncystic fibrosis bronchiectasis: a systematic review. European Respiratory Journal 2014;44(2):382-93. [PUBMED: 24925920]

\section{Chalmers 2012}

Chalmers JD, Smith MP, McHugh BJ, Doherty C, Govan JR, Hill AT. Short- and long-term antibiotic treatment reduces airway and systemic inflammation in non-cystic fibrosis bronchiectasis. American Journal of Respiratory and Critical Care Medicine 2012;186(7):657-65. [PUBMED: 22744718]

\section{Chalmers 2013}

Chalmers JD, Hill AT. Mechanisms of immune dysfunction and bacterial persistence in non-cystic fibrosis bronchiectasis. Molecular Immunology 2013;55(1):27-34. [PUBMED: 23088941]

\section{Chalmers 2014}

Chalmers JD, Goeminne P, Aliberti S, McDonnell MJ, Lonni S, Davidson J, et al. The bronchiectasis severity index. An international derivation and validation study. American Journal of Respiratory and Critical Care Medicine 2014;189(5):576-85. [PUBMED: 24328736]

\section{Chalmers 2015}

Chalmers JD, Aliberti S, Blasi F. Management of bronchiectasis in adults. European Respiratory Journal 2015;45(5):1446-62. [PUBMED: 25792635]

\section{Chang 2002}

Chang AB, Grimwood K, Mulholland EK, Torzillo PJ. Bronchiectasis in indigenous children in remote Australian communities. Medical Journal of Australia 2002;177(4):200-4. [PUBMED: 12175325]

\section{Chang 2010}

Chang AB, Bell SC, Byrnes CA, Grimwood K, Holmes PW, King PT, et al. Chronic suppurative lung disease and bronchiectasis in children and adults in Australia and New Zealand. Medical Journal of Australia 2010;193(6):356-65. [PUBMED: 20854242]

\section{Cole 1986}

Cole PJ. Inflammation: a two-edged sword - the model of bronchiectasis. European Journal of Respiratory Diseases. Supplement 1986;147:6-15. [PUBMED: 3533593]

\section{Cole 1997}

Cole P. The damaging role of bacteria in chronic lung infection. Journal of Antimicrobial Chemotherapy 1997;40 Suppl A:5-10. [PUBMED: 9484867]

\section{de la Rosa 2016}

de la Rosa D, Martínez-García MA, Olveira C, Girón R, Máiz L, Prados C. Annual direct medical costs of bronchiectasis treatment: Impact of severity, exacerbations, chronic bronchial colonization and chronic obstructive pulmonary disease coexistence. Chronic Respiratory Disease 2016;13(4):361-71. [PUBMED: 27072020]

\section{Edwards 2000}

Edwards IR, Aronson JK. Adverse drug reactions: definitions, diagnosis, and management. Lancet 2000;356(9237):1255-9. [PUBMED: 11072960]

\section{Elborn 2016}

Elborn JS, Vataire A-L, Fukushima A, Aballea S, Khemiri A, Moore $\mathrm{C}$, et al. Comparison of inhaled antibiotics for the treatment of chronic pseudomonas aeruginosa lung Infection in patients with cystic fibrosis: systematic literature review and network meta-analysis. Clinical Therapeutics 2016;8(8):1-23. 


\section{European Lung White Book 2013}

Gibson GJ, Loddenkemper R, Sibille Y, Lundbäck B, editor(s). European Lung White Book: Respiratory Health and Disease in Europe. European Lung White Book: Respiratory Health and Disease in Europe. European Respiratory Society, 2013. [www.erswhitebook.org]

\section{Evans 1996}

Evans SA, Turner SM, Bosch BJ, Hardy CC, Woodhead MA. Lung function in bronchiectasis: the influence of Pseudomonas aeruginosa. European Respiratory Journal 1996;9(8):1601-4. [PUBMED: 8866579]

\section{Finch 2015}

Finch S, McDonnell MJ, Abo-Leyah H, Aliberti S, Chalmers JD. A comprehensive analysis of the impact of Pseudomonas aeruginosa colonization on prognosis in adult bronchiectasis. Annals of the American Thoracic Society 2015;12(11):1602-11. [PUBMED: 26356317]

\section{Foweraker 2011}

Foweraker J, Wat D. Microbiology of non-CF bronchiectasis [Bronchiectasis]. In: Floto RA, Haworth CS editor(s). European Respiratory Society Monographs. Vol. 52, European Respiratory Society, 2011:68-96.

\section{Goeminne 2016}

Goeminne PC, De Soyza A. Bronchiectasis: how to be an orphan with many parents?. European Respiratory Journal 2016;47(1):10-3. [PUBMED: 26721955]

\section{GRADEpro GDT [Computer program]}

McMaster University (developed by Evidence Prime). GRADEpro GDT. Version accessed 30 January 2017. Hamilton (ON): McMaster University (developed by Evidence Prime), 2015.

\section{Habesoglu 2011}

Habesoglu MA, Ugurlu AO, Eyuboglu FO. Clinical, radiologic, and functional evaluation of 304 patients with bronchiectasis. Annals of Thoracic Medicine 2011;6(3):131-6. [PUBMED: 21760844]

\section{Hansen 2015}

Hansen MP, Thorning S, Aronson JK, Beller EM, Glasziou PP, Hoffmann TC, et al. Adverse events in patients taking macrolide antibiotics versus placebo for any indication. Cochrane Database of Systematic Reviews 2015, Issue 8. [DOI: 10.1002/14651858.CD011825]

\section{Haworth 2014}

Haworth CS, Foweraker JE, Wilkinson P, Kenyon RF, Bilton D. Inhaled colistin in patients with bronchiectasis and chronic Pseudomonas aeruginosa infection. American Journal of Respiratory and Critical Care Medicine 2014;189(8):975-82. [PUBMED: 24625200]

\section{Higgins 2011}

Higgins JP, Green S (editors). Cochrane Handbook for Systematic Reviews of Interventions Version 5.1.0 (updated March 2011). The Cochrane Collaboration, 2011. Available from handbook.cochrane.org.

\section{Hill 2017}

Hill AT, Haworth CS, Aliberti S, Barker A, Blasi F, Boersma W, et al. Pulmonary exacerbation in adults with bronchiectasis: a consensus definition for clinical research. European Respiratory Journal 2017;49(6):pii: 1700051.

\section{Hnin 2015}

Hnin K, Nguyen C, Carson KV, Evans DJ, Greenstone M, Smith BJ. Prolonged antibiotics for non-cystic fibrosis bronchiectasis in children and adults. Cochrane Database of Systematic Reviews 2015, Issue 8. [DOI: 10.1002/14651858.CD001392.pub3]

\section{Hui 2013}

Hui C, Lin MC, Jao MS, Liu TC, Wu RG. Previous antibiotic exposure and evolution of antibiotic resistance in mechanically ventilated patients with nosocomial infections. Journal of Critical Care 2013;28(5):728-34. [DOI: 10.1016/j.jcrc.2013.04.008]

\section{Joish 2013}

Joish VN, Spilsbury-Cantalupo M, Operschall E, Luong B, Boklage S. Economic burden of non-cystic fibrosis bronchiectasis in the first year after diagnosis from a US health plan perspective. Applied Health Economics and Health Policy 2013;11(3):299-304. [PUBMED: 23580074]

\section{Kapur 2012}

Kapur N, Masters IB, Newcombe P, Chang AB. The burden of disease in pediatric non-cystic fibrosis bronchiectasis. Chest 2012;141(4):1018-24. [PUBMED: 21885727]

\section{Littlewood 2012}

Littlewood KJ, Higashi K, Jansen JP, Capkun-Niggli G, Balp MM, Doering G, et al. A network meta-analysis of the efficacy of inhaled antibiotics for chronic Pseudomonas infections in cystic fibrosis. Journal of Cystic Fibrosis 2012;11(5):419-26. [DOI: 10.1016/j.jcf.2012.03.010]

\section{Martínez-García 2007}

Martínez-García MA, Soler-Cataluña JJ, Perpiñá-Tordera M, Román-Sánchez P, Soriano J. Factors associated with lung function decline in adult patients with stable non-cystic fibrosis bronchiectasis. Chest 2007;132(5):1565-72. [PUBMED: 17998359]

\section{Martínez-García 2018}

Martínez-García MÁ, Máiz L, Olveira C, Girón RM, de la Rosa D, Blanco M. Spanish guidelines on treatment of bronchiectasis in adults. Archivos de Bronconeumología (English Edition) 2018;54(2):88-98. [DOI: 10.1016/j.arbres.2017.07.016]

\section{McCullough 2014}

McCullough AR, Tunney MM, Quittner AL, Elborn JS, Bradley JM, Hughes CM. Treatment adherence and health outcomes in patients with bronchiectasis. BMC Pulmonary Medicine 2014;14:107. [PUBMED: 24980161]

\section{Melnyk 2015}

Melnyk AH, Alex Wong A, Kassen R. The fitness costs of antibiotic resistance mutations. Evolutionary Applications 2015;8(3):27383. 


\section{Moher 2009}

Moher D, Liberati A, Tetzlaff J, Altman D. Preferred reporting items for systematic reviews and meta-analyses: the PRISMA statement. PLoS Medicine 2009;6(7):e1000097. [DOI: 10.1371/ journal.pmed.1000097]

\section{Murray 2011}

Murray MP, Govan JRW, Doherty CJ, Simpson AJ, Wilkinson TS, Chalmers JD, et al. A randomized controlled trial of nebulized gentamicinin non-cystic fibrosis bronchiectasis. American Journal of Respiratory and Critical Care Medicine 2011;183:4919.

\section{Pasteur 2010}

Pasteur MC, Bilton D, Hill AT, British Thoracic Society Bronchiectasis (non-CF) Guideline Group. British Thoracic Society Guidelines for non-CF bronchiectasis. Thorax 2010;65(Suppl1):i1-58.

\section{Polverino 2017}

Polverino E, Goeminne PC, McDonnell MJ, Aliberti S, Marshall SE, Loebinger MR, et al. European Respiratory Society guidelines for the management of adult bronchiectasis. European Respiratory Journal 2017;50(3):pii: 1700629. [DOI: 10.1183/13993003.00629-2017]

\section{Quint 2016}

Quint JK, Millett ER, Joshi M, Navaratnam V, Thomas SL, Hurst JR, et al. Changes in the incidence, prevalence and mortality of bronchiectasis in the UK from 2004 to 2013: a population-based cohort study. European Respiratory Journal 2016;47(1):186-93. [PUBMED: 26541539]

\section{Redondo 2016}

Redondo M, Keyt H, Dhar R, Chalmers JD. Global impact of bronchiectasis and cystic fibrosis. Breathe 2016;12(3):222-35.

\section{Review Manager 2014 [Computer program]}

Nordic Cochrane Centre, The Cochrane Collaboration. Review Manager 5 (RevMan 5). Version 5.3. Copenhagen: Nordic Cochrane Centre, The Cochrane Collaboration, 2014.

\section{Ringshausen 2015}

Ringshausen FC, de Roux A, Diel R, Hohmann D, Welte T, Rademacher J. Bronchiectasis in Germany: a population-based estimation of disease prevalence. European Respiratory Journal 2015;46(6):1805-7. [PUBMED: 26293498]

\section{Roberts 2010}

Roberts HJ, Hubbard R. Trends in bronchiectasis mortality in England and Wales. Respiratory Medicine 2010;104:981-5.

\section{CHARACTERISTICS OF STUDIES}

Characteristics of excluded studies [ordered by study ID]

\section{Rogers 2014}

Rogers GB, Zain NM, Bruce KD, Burr LD, Chen AC, Rivett DW, et al. A novel microbiota stratification system predicts future exacerbations in bronchiectasis. Annals of the American Thoracic Society 2014;11(4):496-503. [PUBMED: 24592925]

\section{Seitz 2010}

Seitz AE, Olivier KN, Steiner CA, Montes de Oca R, Holland SM, Prevots DR. Trends and burden of bronchiectasis-associated hospitalizations in the United States, 1993-2006. Chest 2010;138(4):944-9. [PUBMED: 20435655]

\section{Serisier 2013}

Serisier DJ, Martin ML, McGuckin MA, Lourie R, Chen AC, Brain B, et al. Effect of long-term, low-dose erythromycin on pulmonary exacerbations among patients with non-cystic fibrosis bronchiectasis: the BLESS randomized controlled trial. JAMA 2013;309(12):1260-7. [PUBMED: 23532242]

\section{Twiss 2005}

Twiss J, Metcalfe R, Edwards E, Byrnes C. New Zealand national incidence of bronchiectasis "too high" for a developed country. Archives of Disease in Childhood 2005;90(7):737-40. [PUBMED: 15871981]

\section{Weycker 2005}

Weycker D, Edelsberg J, Oster G, Tino G. Prevalence and economic burden of bronchiectasis. Clinical Pulmonary Medicine 2005;12(4):205-9.

\section{Wilson 1997}

Wilson CB, Jones PW, O'Leary CJ, Hansell DM, Cole PJ, Wilson R. Effect of sputum bacteriology on the quality of life of patients with bronchiectasis. European Respiratory Journal 1997;10(8):1754-60. [PUBMED: 9272915]

\section{Wilson 2013}

Wilson R, Welte T, Polverino E, De Soyza A, Greville H, O'Donnell A, et al. Ciprofloxacin dry powder for inhalation in non-cystic fibrosis bronchiectasis: a phase II randomised study. European Respiratory Journal 2013;41:1107-115.

\section{Wong 2012}

Wong C, Jayaram L, Karalus N, Eaton T, Tong C, Hockey H, et al. Azithromycin for prevention of exacerbations in non-cystic fibrosis bronchiectasis (EMBRACE): a randomised, doubleblind, placebo-controlled trial. Lancet 2012;380(9842):660-7. [PUBMED: 22901887]

Study Reason for exclusion




\begin{tabular}{|c|c|}
\hline Study & Reason for exclusion \\
\hline Aksamit 2017 & $\begin{array}{l}\text { Comparison between ciprofloxacin (intermittent for } 28 \text { days) versus ciprofloxacin (intermittent for } \\
14 \text { days) versus placebo }\end{array}$ \\
\hline Al-Mobeireek 1998 & $\begin{array}{l}\text { Study to determine the range and sensitivity of bacterial pathogens in infective exacerbations of } \\
\text { bronchiectasis }\end{array}$ \\
\hline Alberto 1968 & $\begin{array}{l}\text { Randomised comparison of thiamphenicol glycinate plus acetylcysteine (FZ280E) versus thi- } \\
\text { amphenicol glycinate in chronic bronchopulmonary disease }\end{array}$ \\
\hline Alekseenko 1978 & $\begin{array}{l}\text { Comparison between antibiotics with direct current intervention versus antibiotics alone in the } \\
\text { treatment of inflammatory suppurative diseases of the lungs }\end{array}$ \\
\hline Alekseenko 1980 & Not a randomised trial. Study focusing on antibiotics and bronchial sanitations \\
\hline Aliberti 2016 & Not a randomised trial. Consensus statement on the management of bronchiectasis \\
\hline Antoniu 2013 & Comparison between ciprofloxacin versus placeb \\
\hline Cherniack 1959 & $\begin{array}{l}\text { Not a randomised trial. Comparison among placebo versus tetracycline versus oleandomycin-peni- } \\
\text { cillin versus penicillin }\end{array}$ \\
\hline ChiCTR-IOR-16008910 2016 & $\begin{array}{l}\text { Comparison between procalcitonin versus control (conventional treatment). Study yet to be com- } \\
\text { pleted in } 2017\end{array}$ \\
\hline Chonabayasi 1988 & Not a randomised trial. Before and after comparison of T-3262 in respiratory infections \\
\hline Choo 2018 & Comparison between erythromycin versus placebo \\
\hline Cseri 1975 & $\begin{array}{l}\text { No indication of randomisation. Comparison between sumetrolim versus oxytetracycline for chron- } \\
\text { ic non-specific respiratory tract infections }\end{array}$ \\
\hline Currie 1987 & Comparison between amoxycillin versus placebo \\
\hline Dimakou 2017 & Comparison between tobramycin versus colistin \\
\hline Douglas 1957 & Comparison between chloramphenicol versus oxytetracycline \\
\hline Hayashi 1989 & Not a randomised trial. Evaluation of cefdinir in the treatment of pneumonia \\
\hline Hill 1992 & Comparison between 200 mg twice daily versus 400 mg twice daily of loracarbef (LY 163892). \\
\hline Howie 1976 & Letter \\
\hline Huang 2018 & Comparison between herbal decoction with standard decoction \\
\hline Hughes 1973 & Comparison between trimethoprim and ampicillin \\
\hline Iglauer 1973 & Comparison between trimethoprim versus sulphamethoxazol \\
\hline Inoue 1989 & Not a randomised trial. Evaluation of 7432-S \\
\hline Irabu 1989 & Not a randomised trial. Evaluation of cefdinir \\
\hline Irabu 1992 & Not a randomised trial. Evaluation of ME1207 \\
\hline
\end{tabular}




\begin{tabular}{|c|c|}
\hline Study & Reason for exclusion \\
\hline Juthong 2011 & Comparison between roxithromycin versus placebo \\
\hline Kanai 1963 & Spectrophotometric examination of the respiratory chain \\
\hline Kawano 1974 & Comparison between 200 mg versus 400 mg of amikacin \\
\hline Kawashima 1989 & $\begin{array}{l}\text { Not a randomised trial. Observational study of branhamella catarrhalis infection in pulmonary dis- } \\
\text { orders }\end{array}$ \\
\hline Koyama 1992 & Not a randomised trial. Evaluation of ME1207 \\
\hline Krawczyk 1981 & Not a randomised trial. Evaluation of antibiotics and biceptol preparation \\
\hline Kudo 1992 & Not a randomised trial. Evaluation of ME1207 \\
\hline Kurishima 1992 & Not a randomised trial. Evaluation of cefclidin \\
\hline Kuze 1988 & Not a randomised trial. Evaluation of cefodizime (THR-221) in respiratory tract infections \\
\hline Lamotte 1981 & Not a randomised trial. Overview of bronchiectasis \\
\hline Ledson 2000 & Not a randomised trial. $\mathrm{N}$ of 1 study of nebulised taurolidine \\
\hline Lunacharskaia 1968 & Evaluation of intratracheal administration of morphocycline \\
\hline Maekawa 1967 & Study did not include participants with bronchiectasis \\
\hline Matsumoto 1984 & Not a randomised trial. Evaluation of lenampicillin (KBT-1585) in respiratory infection \\
\hline Matsumoto 1992 & Not a randomised trial. Evaluation of ME1207 in the treatment of respiratory tract infection \\
\hline Matsuura 1993 & Not a randomised trial. Evaluation of S-1108 in elderly patients \\
\hline May 1974 & Comparison between amoxicillin versus ampicillin \\
\hline Mazzei 1993 & Not a randomised trial. Evaluation of ciprofloxacin for lower respiratory tract infections \\
\hline Messens 1973 & $\begin{array}{l}\text { Comparison between sulfamethoxazoletrimethoprim versus demethylchlortetracycline in the } \\
\text { treatment of pulmonary infections }\end{array}$ \\
\hline
\end{tabular}

$\begin{array}{ll}\text { Milcev } 1985 & \begin{array}{l}\text { Focus of this before and after comparison was on anaerobic pulmonary infections and their resis- } \\ \text { tance to antibiotics }\end{array}\end{array}$
tance to antibiotics

\begin{tabular}{ll}
\hline Ming 2005 & Comparison between macrolide with theophylline versus 'necessary antibiotics' \\
\hline Molodtsova 1980 & $\begin{array}{l}\text { Evaluation of penicillin, streptomycin, monomycin, levomycetin zeporin, chemotripcin and gi- } \\
\text { grolitin }\end{array}$ \\
\hline Morrone 1989 & $\begin{array}{l}\text { Participants were randomised to receive } 400 \text { mg versus } 800 \text { mg of Ofloxacin, two doses per day for } \\
10 \text { days for a total of } 400 \text { mg per day or } 800 \text { mg per day. Comparison therefore not intermittent ver- } \\
\text { sus continuous }\end{array}$
\end{tabular}




\begin{tabular}{|c|c|}
\hline Study & Reason for exclusion \\
\hline Nagy 1968 & Not a randomised trial \\
\hline Nakagawa 1989 & Not a randomised trial. Evaluation of cefdinir in respiratory tract infections \\
\hline Nakagawa 1993 & Not a randomised trial \\
\hline Nasu 1988 & Not a randomised trial. Evaluation of T-3262 in respiratory tract infections \\
\hline NCT00415350 & Comparison between azithromycin versus placebo \\
\hline NCT00524095 & $\begin{array}{l}\text { Comparison between fluticasone versus azithromycin (study terminated and did not proceed to } \\
\text { treatment phase }\end{array}$ \\
\hline NCT00775138 & Comparison between $280 \mathrm{mg}$ versus $560 \mathrm{mg}$ arikace versus placebo \\
\hline NCT00889967 & Comparison between ciprofloxacin versus placebo \\
\hline NCT00930982 & Comparison between ciprofloxacin versus placebo \\
\hline NCT01313624 & Comparison between aztreonam versus placebo \\
\hline NCT01515007 & Comparison between iprofloxacin for Inhalation versus placebo liposomes for inhalation \\
\hline NCT01538667 & $\begin{array}{l}\text { Evaluation of lung deposition, pharmacokinetics, safety and tolerability of ciprofloxacin dry pow- } \\
\text { der }\end{array}$ \\
\hline NCT01761214 & Not a randomised trial. Evaluation of fluroquinolones \\
\hline NCT02035488 & Not a randomised trial. Evaluation of tobramycin \\
\hline NCT02047773 & Evaluation of bacterial load guided therapy \\
\hline NCT02081963 & Comparison between amikacin and normal saline \\
\hline NCT02102152 & Comparison between tobramycin versus placebo \\
\hline NCT02104245 & Comparison between pulmaquin versus placebo \\
\hline NCT02107274 & Comparison between azithromycin versus placebo \\
\hline NCT02315547 & Not a randomised trial. Comparison between bronchiectasis patients and healthy participants \\
\hline NCT02491723 & Not a randomised trial. Evaluation of azithromycin \\
\hline NCT02509091 & $\begin{array}{l}\text { Fundamental treatment combining with the therapy of bronchoalveolar lavage and local amikacin } \\
\text { injection versus fundamental treatment alone }\end{array}$ \\
\hline NCT02657473 & Comparison between tobramycin inhalation solution and saline inhalation solution \\
\hline NCT02661438 & Not a randomised trial. Evaluation of ciprofloxacin \\
\hline NCT03058718 & Evaluation of procalcitonin-guided antibiotic therapy \\
\hline NCT03093974 & Comparison between colistimethate sodium versus saline solution \\
\hline
\end{tabular}




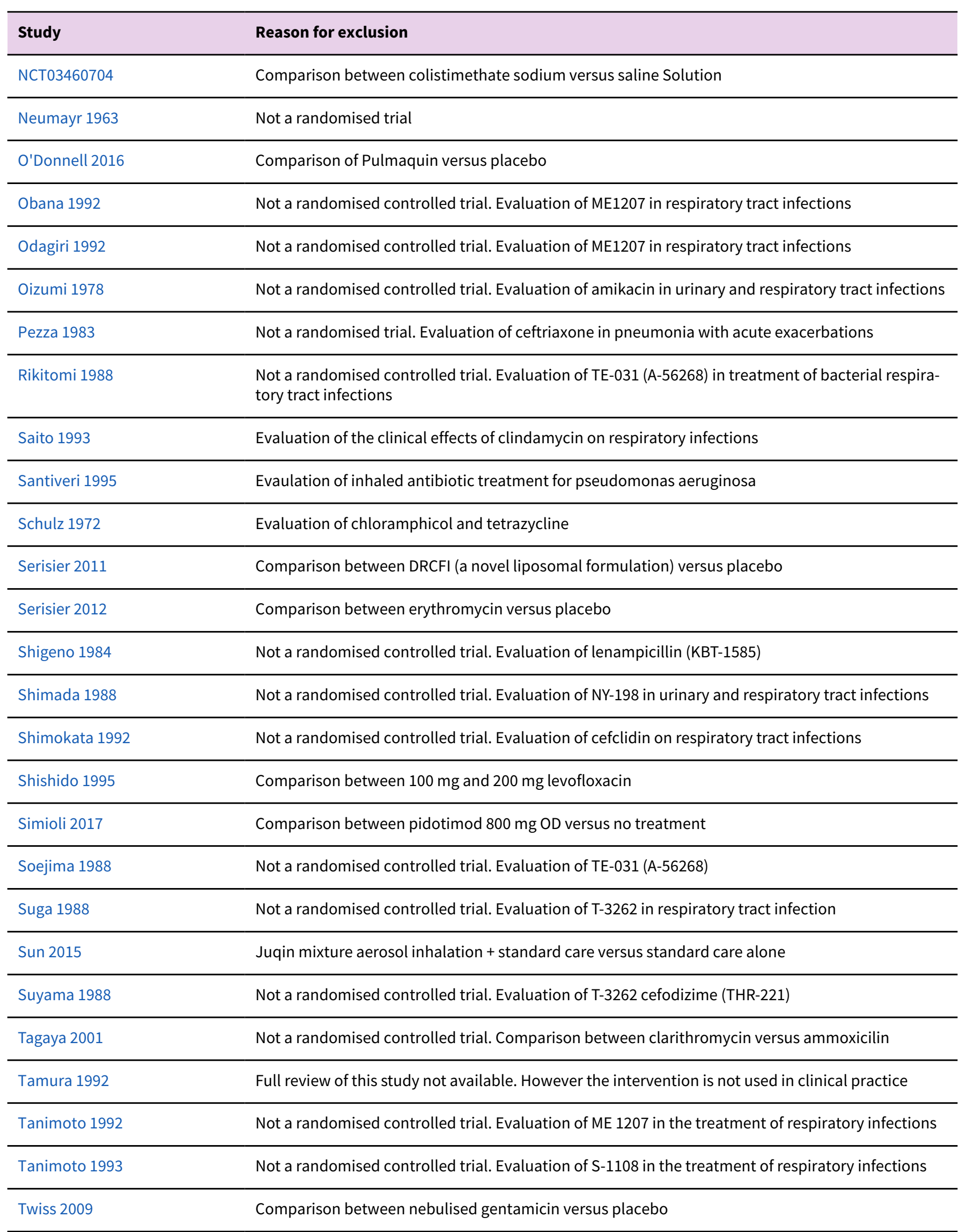




\begin{tabular}{ll}
\hline Study & Reason for exclusion \\
\hline Wada 1992 & $\begin{array}{l}\text { Not a randomised controlled trial and not participants with bronchiectasis. Respiratory tract infec- } \\
\text { tions }\end{array}$ \\
\hline Watanabe 1988 & Not a randomised controlled trial and not participants with bronchiectasis \\
\hline Watanabe 1991 & Not a randomised controlled trial \\
\hline Watanabe 1995 & Not a randomised controlled trial \\
\hline Weston 1966 & Not a randomised controlled trial and not participants with bronchiectasis. Chronic bronchitis \\
\hline Wilson 2011 & Comparison with placebo \\
\hline Wong 2004 & Comparison between levofloxacin versus ceftazidime \\
\hline Yamada 1993 & Not a randomised controlled trial and not participants with bronchiectasis. \\
\hline Yoshida 1989 & Not a randomised controlled trial and not participants with bronchiectasis. \\
\hline Zegaya 1981 & Not a randomised controlled trial. Evaluation of doxycycline in pleuropulmonary affections \\
\hline
\end{tabular}

\section{Characteristics of ongoing studies [ordered by study ID]}

\section{NCT02712983}

Trial name or title

Dose-finding Study to Assess the Efficacy, Safety and Tolerability of Tobramycin Inhalation Powder in Patients With Non-Cystic Fibrosis Bronchiectasis and Pulmonary P. Aeruginosa Infection (iBEST-1)

\begin{tabular}{ll}
\hline Methods & Parallel group randomized trial \\
\hline Participants & Patients with non-cystic fibrosis bronchiectasis and pulmonary P Aeruginosa infection \\
\hline Interventions & tobramycin inhalation powder (TIP) dose and placebo, 3 dose regimens \\
\hline Outcomes & Paeruginosa density in sputum \\
\hline Starting date & 2 February 2017 \\
\hline Contact information & Novartis Pharmaceuticals: email: trialandresults.registries@novartis.com \\
\hline Notes & Estimated completion date: 10 September 2018 \\
\hline
\end{tabular}

\section{AP PEN DICES}

\section{Appendix 1. Sources and search methods for the Cochrane Airways Group's Specialised Register (CAGR) Electronic searches: core databases}




\begin{tabular}{ll}
\hline Database & Frequency of search \\
\hline CENTRAL (the Cochrane Library) & Monthly \\
\hline MEDLINE (Ovid) & Weekly \\
\hline Embase (Ovid) & Weekly \\
\hline PsycINFO (Ovid) & Monthly \\
\hline CINAHL (EBSCO) & Monthly \\
\hline AMED (EBSCO) & Monthly \\
\hline
\end{tabular}

\section{Handsearches: core respiratory conference abstracts}

\begin{tabular}{ll}
\hline Conference & Years searched \\
\hline American Academy of Allergy, Asthma and Immunology (AAAAI) & 2001 onwards \\
\hline American Thoracic Society (ATS) & 2001 onwards \\
\hline Asia Pacific Society of Respirology (APSR) & 2004 onwards \\
\hline British Thoracic Society Winter Meeting (BTS) & 2000 onwards \\
\hline Chest Meeting & 2003 onwards \\
\hline European Respiratory Society (ERS) & $1992,1994,2000$ onwards \\
\hline International Primary Care Respiratory Group Congress (IPCRG) & 2002 onwards \\
\hline Thoracic Society of Australia and New Zealand (TSANZ) & 1999 onwards \\
\hline
\end{tabular}

\section{MEDLINE search strategy used to identify studies for the CAGR \\ Condition search}
1. exp Asthma/
2. asthma\$.mp.
3. (antiasthma\$ or anti-asthma\$).mp.
4. Respiratory Sounds/
5. wheez\$.mp.
6. Bronchial Spasm/
7. bronchospas\$.mp.
8. (bronch\$ adj3 spasm\$).mp.
9. bronchoconstrict\$.mp. 
10. exp Bronchoconstriction/

11. (bronch\$ adj3 constrict\$).mp.

12. Bronchial Hyperreactivity/

13. Respiratory Hypersensitivity/

14. ((bronchial\$ or respiratory or airway\$ or lung\$) adj3 (hypersensitiv\$ or hyperreactiv\$ or allerg\$ or insufficiency)).mp.

15. ((dust or mite\$) adj3 (allerg\$ or hypersensitiv\$)).mp.

16. or/1-15

17. exp Aspergillosis, Allergic Bronchopulmonary/

18. lung diseases, fungal/

19. aspergillosis/

20. 18 and 19

21. (bronchopulmonar\$ adj3 aspergillosis).mp.

22. 17 or 20 or 21

23. 16 or 22

24. Lung Diseases, Obstructive/

25. exp Pulmonary Disease, Chronic Obstructive/

26. emphysema\$.mp.

27. (chronic\$ adj3 bronchiti\$).mp.

28. (obstruct\$ adj3 (pulmonary or lung\$ or airway\$ or airflow\$ or bronch\$ or respirat\$)).mp.

29. COPD.mp.

30. COAD.mp.

31. COBD.mp

32. AECB.mp.

33. or/24-32

34. exp Bronchiectasis/

35. bronchiect\$.mp.

36. bronchoect\$.mp.

37. kartagener\$.mp.

38. (ciliary adj3 dyskinesia).mp.

39. (bronchial\$ adj3 dilat\$).mp.

40. or/34-39

41. exp Sleep Apnea Syndromes/

42. (sleep\$ adj3 (apnoea\$ or apnoea\$)).mp.

43. (hypopnoea\$ or hypopnoea\$).mp.

44. OSA.mp

Continuous versus intermittent antibiotics for bronchiectasis (Review) 
45. SHS.mp.

46. OSAHS.mp.

47. or/41-46

48. Lung Diseases, Interstitial/

49. Pulmonary Fibrosis/

50. Sarcoidosis, Pulmonary/

51. (interstitial\$ adj3 (lung\$ or disease\$ or pneumon\$)).mp.

52. ((pulmonary\$ or lung\$ or alveoli\$) adj3 (fibros\$ or fibrot\$)).mp.

53. ((pulmonary\$ or lung\$) adj3 (sarcoid\$ or granulom\$)).mp.

54. or/48-53

55.23 or 33 or 40 or 47 or 54

\section{Filter to identify RCTs}

1. exp "clinical trial [publication type]"/

2. (randomised or randomised).ab,ti.

3. placebo.ab,ti.

4. dt.fs.

5. randomly.ab,ti.

6. trial.ab,ti.

7. groups.ab,ti.

8. or/1-7

9. Animals/

10. Humans/

11. 9 not (9 and 10)

12. 8 not 11

The MEDLINE strategy and RCT filter are adapted to identify studies in other electronic databases

\section{Appendix 2. Search strategy to identify relevant studies from the CAGR}

\#1 BRONCH:MISC1

\#2 MeSH DESCRIPTOR Bronchiectasis Explode All

\#3 bronchiect $^{\star}$

\#4 \#1 or \#2 or \#3

\#5 MeSH DESCRIPTOR Anti-Bacterial Agents Explode 1

\#6 antibiotic* or anti-biotic*

\#7 anti-bacteri* or antibacteri ${ }^{\star}$

\#8 *illin

\#9 * mycin or micin* 
\#10 *oxacin

\#11 *tetracycline

\#12 macrolide ${ }^{*}$

\#13 quinolone*

\#14 trimethoprim

\#15 ceph* $^{\star}$

\#16 sulpha*

$\# 17 \# 5$ or \#6 or \#7 or \#8 or \#9 or \#10 or \#11 or \#12 or \#13 or \#14 or \#15 or \#16

\#18 \#4 and \#17

[In search line \#1, MISC1 denotes the field in the record where the reference has been coded for condition, in this case, bronchiectasis]

\section{CONTRIBUTIONS OF AUTHORS}

All review authors contributed to the Background section. LF and SS contributed to the Methods section. SM and TD screened the searches. All authors contributed to results, discussion and conclusions.

\section{DECLARATIONS OF INTEREST}

J Chalmers: part of the EMBARC group that set research priorities in bronchiectasis. He also receives grant support from Pfizer, AstraZeneca and GlaxoSmithKline. In addition, he is part of an innovative medicines initiative consortium that includes Novartis and Basilea Pharmaceutica. He has participated in advisory boards for Bayer HealthCare, Chiesi and Raptor Pharmaceuticals. He has received fees for speaking from Napp, AstraZeneca, BI and Pfizer. None of these conflicts of interest are related to the work of this review and are unrelated to the topic of the review.

T Donovan: none known.

L Felix: none known.

A Mathioudakis: none known.

S Milan: none known.

S Spencer: named co-investigator on a study conducted to develop a series of reviews on bronchiectasis.

\section{SOURCES OF SUPPORT}

\section{Internal sources}

- Edge Hill University, UK.

Funded Lambert Felix to provide support for a series of reviews on bronchiectasis.

\section{External sources}

- National Institute of Health Research, UK.

AGM was funded by an NIHR Academic Clinical Fellowship in Respiratory Medicine

\section{DIFFERENCES BETWEEN PROTOCOLANDREVIEW}

No differences.

\section{N DEX TERMS}

\section{Medical Subject Headings (MeSH)}

Anti-Bacterial Agents [administration \& dosage] [*therapeutic use]; Bronchiectasis [* drug therapy] 


\section{MeSH check words}

Adult; Child; Humans 